\title{
STRATEGIC FEEDBACK IN TEAMS: THEORY AND EXPERIMENTAL EVIDENCE
}

\author{
Seda Ertaç \\ Mert Gümren \\ Levent Koçkesen
}

Working Paper 1714

September 2017

This Working Paper is issued under the supervision of the ERF Directorate. Any opinions expressed here are those of the author(s) and not those of the Koç University-TÜSİAD Economic Research Forum. It is circulated for discussion and comment purposes and has not been subject to review by referees.

KOÇ UNIVERSITY-TÜSİAD ECONOMIC RESEARCH FORUM

Rumelifeneri Yolu 34450 Sariyer/Istanbul 


\title{
Strategic Feedback in Teams: Theory and Experimental Evidence ${ }^{*}$
}

\author{
Seda $\operatorname{Ertac}^{\dagger}$ \\ Koç University
}

\author{
Mert Gümren \\ Koç University
}

\author{
Levent Koçkesen \\ Koç University
}

August 2017

\begin{abstract}
We theoretically and experimentally analyze public and private feedback in teams that are characterized by different performance technologies. We consider a setting where the principal can provide truthful information on agents' performances or strategically withhold feedback. We find that if team performance is determined by the best performer (the "best-shot technology"), then both public and private feedback are better than no feedback unless the team is composed of all low performers, in which case no feedback is best. If, on the other hand, team performance is determined by the worst performer (the weakest-link technology), then no feedback is the best regime unless the team is composed of all high performers, in which case public or private feedback is better. Our results have implications for performance feedback policies in educational settings and the workplace.
\end{abstract}

Keywords: Lab experiments, Feedback, Performance feedback, Teams, Strategic communication, Disclosure games, Multiple audiences

JEL Classification: C72, C92, D23, D82, D83, M12, M54.

${ }^{*}$ Seda Ertac, Department of Economics, Koç University, Rumelifeneri Yolu Sariyer, Istanbul 34450 Turkey. E-mail: sertac@ku.edu.tr. Mert Gümren, Department of Economics, Koç University. Levent Koçkesen, Department of Economics, Koç University. Ertac thanks the Scientific and Technological Research Council of Turkey (TUBITAK) for generous financial support (Grant No. 111K444) for the experiments in this paper, and the Turkish Academy of the Sciences (GEBIP program) and the Science Academy (BAGEP program) for general support.

${ }^{\dagger}$ Corresponding author. 


\section{Introduction}

Former Manchester United manager Louis van Gaal used to conduct evaluation sessions the day after every match, where he would publicly criticize players. Wayne Rooney and Michael Carrick, the most senior players, "went to see him to air their concerns that it was damaging for morale and, in effect, a self-defeating exercise." After the complaints, he started sending individualized emails to the players detailing his feedback, but these were mostly ignored by the players. Van Gaal didn't give up and started using a tracker to check if the emails were opened and for how long. Players found a way to evade this tactic as well. The team was not happy and Van Gaal was fired two years into his contract. ${ }^{1}$

Although performance feedback is a ubiquitous organizational practice, it has been a subject of intense debate in business circles and in recent years many companies have completely abandoned it. Samuel Culbert of UCLA, a critique well-known in business circles, states that "[i]t's a negative to corporate performance, an obstacle to straight-talk relationships, and a prime cause of low morale at work."(Culbert [2008]). Recent research from CEB, a management research firm, has found that neither employees nor managers are happy with the process. "They find it time-consuming and ineffective in boosting performance and say it doesn't correlate to business results." However, CEB research has also found that companies that dropped the ratings aspect of performance review have subsequently experienced a decline in employee performance. ${ }^{2}$ There is also discussion about whether to give feedback privately or publicly, particularly in team settings. A Harvard Business Review article reports that "The management mantra for giving individuals feedback is: "Praise in public, criticize in private." But in team settings, this goes out the window, according to Schwarz." (Knight [2016]). ${ }^{3}$

In other words, there is quite a bit of uncertainty in the business world regarding what type of feedback works, if at all, and under what kind of circumstances. How to give feedback to students is a paramount issue in education as well, where it is important to preserve academic motivation and morale (Azmat and Iriberri [2010], Goulas and Megalokonomou [2015]).

In this paper, we theoretically and experimentally analyze the effect of feedback on team performance along two dimensions: (1) Type of feedback (private vs. public) and (2) team technology (weakest-link vs. best-shot). The team in question could be a football team preparing for the next game or a team of individual researchers in an $R \& D$ department working (jointly or separately) on developing a certain drug or technology or a team of graduate students working with the same advisor. Each member's individual performance, or output, depends on his innate ability (or suitability to the task) and his effort (or some other action such as strictness of diet, etc.). The team's success, on the other hand, depends either on the worst performing member (the so called "weakest-link" technology), as may be the case for a product development team (think of the 'exploding' Samsung Galaxy Note 7), or on the best performing member (the "best-shot" technology), as may be the case for a team of researchers working separately on the same project (or a national team of 100 meter sprinters). ${ }^{4}$

We consider a strategic setting where only the the principal (supervisor, manager, coach or ad-

\footnotetext{
${ }^{1}$ The story and the quote in the text is from Taylor [2016].

${ }^{2}$ The quote in the text and the results of the CEB research are from Greenfield [2016].

${ }^{3}$ Schwarz refers to Roger Schwarz, an organizational psychologist and the author of the book Smart Leaders, Smarter Teams.

${ }^{4}$ Obviously, these two technologies are not exhaustive. But we believe they represent situations that are common in many business and educational settings. They have also been used in theoretical and experimental studies of public good contribution (See Hirshleifer [1983] and Harrison and Hirshleifer [1989]).
} 
visor) observes the agents' abilities (or indicators of past performance or suitability to the task) and may choose to provide this information to team members before the next task is performed. Feedback is either private, in which case the principal reports to each agent privately and independently, or public, in which case the same report is received by the entire team. The principal's payoff depends on the team's output, which depends on the team technology (either the maximum or the minimum of the agents' outputs).

We assume that the principal cannot provide false information in her feedback, which might be because false feedback is institutionally prohibited (as in many educational settings) or due to high reputational costs of lying. However, she may choose to withhold it or be vague about it. ${ }^{5}$ As we noted before, we may also think of the abilities as deduced by the principal from the performances of the agents in earlier tasks. Some of these performance measures may indeed be verifiable, i.e., can be reproduced if needed. Some examples are sales or productivity figures, customer ratings, exam or project grades, and evaluations of the agents by higher ranking administrators, co-workers, or customers.

We consider teams with two agents and environments in which effort incentives depend not only on the agent's own ability but also on the other agent's ability. More precisely, we assume that the optimal (or equilibrium) effort of an agent is increasing in own ability and decreasing in the other agent's ability. The first feature could be due to complementarity between effort and ability, which is a common assumption in theoretical models. The second feature is motivated by two considerations: (1) It yields interesting theoretical predictions and (2) we believe it is an empirically relevant feature. It would, for example, arise either directly or in reduced form if there is some underlying competition between the agents (for monetary rewards or status) or strategic substitutability between their efforts. ${ }^{6}$

For each team technology, we compare three different feedback regimes: (1) no feedback, (2) private feedback to each agent on both agents' abilities, and (3) public feedback on both agents' abilities. Our theoretical analysis reveals that whether the principal has an incentive to reveal information depends, in general, on both the type of feedback and the team technology. For example, if the technology is of the "best-shot" variety and the feedback is public, then the principal fully discloses each agent's ability in every equilibrium. If, on the other hand, the technology is of the "weakest-link" variety, then there is only partial information revelation under public feedback.

The main difference between the two technologies can be best understood by considering a heterogenous team, i.e., a team that is composed of one high and one low ability agent. If technology is of the best-shot variety, the principal would like to inform the agent with high ability, since this would maximize the highest ability agent's effort and performance. Therefore, the principal truthfully reveals abilities if only one agent has high ability. But then she would also prefer to reveal when both have high ability because otherwise the agents might believe they both have low ability, which

\footnotetext{
${ }^{5}$ Imprecise feedback, also called the "centrality bias", is well-recognized in the literature. For a discussion of the empirical evidence for centrality bias we refer the reader to Prendergast [1999], who notes that it may well be due to strategic reasons, in particular to avoid discouragement on the part of the workers. Longenecker et al. [1987] report evidence that the main concern of the executives in performance appraisals is not accuracy but rather to motivate and reward subordinates. In the Forbes article titled “Ten Biggest Mistakes Bosses Make In Performance Reviews,” the number 1 item is ‘Too vague' (See Jackson [2012]).

${ }^{6}$ The opposite situation in which the optimal effort is increasing in the other agent's ability is also an empirically relevant case. However, team technology makes a significant difference in terms of theoretical predictions only under the assumption we are working with. We further comment on this issue in Remark 2.
} 
is worse for the principal. Therefore, if feedback is public, the principal's strategy must be fully revealing. If, on the other hand, the technology is of the weakest-link type, then the principal would prefer not to inform the low ability agent. In fact, she would rather let the high ability agent believe that he has low and the other agent has high ability than let the agents learn the truth. ${ }^{7}$ This implies that if only one agent has high ability, the principal prefers not to reveal it. The model specification further implies that, when feedback is public, the principal prefers to reveal information when both agents have high ability and no information when both have low ability. ${ }^{8}$ In other words, the principal reveals information only when both agents have high ability.

When feedback is private, the message space of the principal is richer and the principal can induce different beliefs on different agents. This leads to multiple equilibria for each type of technology: a partially informative equilibrium for the best-shot and a fully informative one for the weakest-link.

The above arguments imply that when the technology is of the best-shot variety, high ability agents are always informed, which, in turn, suggests that feedback is beneficial, except in teams that are exclusively composed of low performers. In contrast, if the technology is of the weakest-link type, agents receive information only when they both have high ability, and in all other cases their beliefs become more pessimistic compared with their prior beliefs. This implies that feedback is likely to be detrimental in weakest-link type situations, except in teams whose members are all high performers.

Our experimental results support these theoretical predictions. We find that if team performance is determined by the best performer, then both public and private feedback are better than no feedback, unless it is known that the team is composed of all low performers, in which case no feedback is best. There is no significant difference between public and private feedback, except when the team is heterogenous, in which case private feedback is better. If, on the other hand, team performance is determined by the weakest link, then no feedback is the best regime unless the team is composed of all high performers, in which case public or private feedback is better. Public feedback is always better than or equivalent to private feedback.

As we have argued above, we predict that public feedback is more informative when the technology is best-shot as opposed to weakest-link, and this receives strong support from the data. Furthermore, we predict that public feedback is more informative than private feedback when the technology is best-shot, while the opposite is the case when the technology is weakest-link. This is exactly what we observe in the data, but the difference is statistically significant (at the $10 \%$ level) only in the bestshot case. In Section 6 we also test other predictions regarding how agents interpret feedback and choose effort as well as predictions on principals' feedback strategy.

The policy implications of these results are clear. If you are the advisor of several graduate students and care only about how the "star" student performs, then a policy of relative feedback on talent is the best policy. If you are instead a Rawlsian advisor and care about how your worst student will fare in the market, a policy of no relative feedback is your best option. Similarly, if you are the leader of an R\&D project on a new technology and each researcher in the team is independently working on this technology, then relative feedback is a good idea. If, instead, each member undertakes a different and essential task for the project, then no relative feedback would be the best policy. ${ }^{9}$

\footnotetext{
${ }^{7}$ This is because it is better to get low effort from the high ability agent than low effort from the low ability agent when the technology is weakest-link.

${ }^{8}$ See the paragraph just before Proposition 2 for details on this last argument.

${ }^{9}$ If we believe that a football team has a technology that is closer to weakest-link than to best-shot, then one of the factors
} 


\section{Related Literature}

This is, to the best of our knowledge, the first theoretical and experimental work on the effect of different types of feedback on the performance of teams that are characterized by different technologies. Our work is related to several strands of literature. The most relevant one is the relatively scant experimental literature on strategic performance feedback. These papers generally study unverifiable feedback in the context of cheap talk games or verifiable feedback in the context of disclosure games. A major focus in this literature is how much information is transmitted in equilibrium. A recent example is Ertac et al. [2016], who study the informativeness of different types of feedback (private vs. public and verifiable vs. unverifiable) in a "one principal two agent" setup with real effort, where the theory predicts that only verifiable feedback is informative. They indeed find that verifiable feedback is more informative, but some principals tell the truth even when feedback is unverifiable, and agents interpret no feedback more optimistically than the theory suggests. The current paper is different along several important dimensions. First of all, our main focus is the effect of feedback on team performance, while they study the informativeness of different types of feedback. ${ }^{10}$ Second, our setup is designed to compare the effects of feedback under different team technologies, i.e., weakest-link and best-shot, while Ertac et al. [2016] uses a single technology. Third, in our model the other agent's type is relevant for effort incentives while it is irrelevant in their paper. This implies that the principal's payoff is monotonic in agents' beliefs in their model, which is not the case in some of our treatments. This is crucial, because it is precisely the reason behind the differences in the effect of feedback on performance across different team technologies.

Ederer and Fehr [2009] study the effect of private and unverifiable feedback on (induced) effort in a dynamic tournament with two agents. They compare strategic feedback (cheap talk) with no feedback and truthful feedback, in a setting where the principal has an incentive to underreport the true performance difference between the agents. In this setting, agents should completely disregard the feedback and therefore, there should be no information transmission in equilibrium. However, experimental results show that even though agents discount the feedback, they still respond to it and some principals provide truthful feedback. Furthermore, average effort is lower under strategic feedback than under no feedback and truthful feedback. ${ }^{11}$

Gürtler and Harbring [2010] also study the effect of relative performance feedback on effort in a tournament setting, but unlike in Ederer and Fehr [2009], feedback is public and verifiable. The theory, in this case, predicts that agents should interpret no feedback as bad news and that there should be full information revelation in equilibrium. They find that although no feedback is indeed regarded as bad news, the effect on effort is not as strong as the theory predicts. Our work differs from these two papers along several lines, but the most important one is the fact that we vary the team technology while they study only tournaments in which the principal's payoff is the sum of the

\footnotetext{
that doomed Van Gaal and Manchester United during his tenure might as well have been his insistence on feedback.

${ }^{10}$ Although their setup is not particularly suited to studying this issue, they report that feedback has no significant effect on performance.

${ }^{11}$ Mohnen and Manthei [2006] and Rosaz [2012] study a one principal-one agent setting with unverifiable feedback. The former paper finds that some principals tell the truth but there is also widespread deception. The latter finds that the principal manipulates the feedback to induce the agent to work and the agent, trusting the principal's message, increases effort in response. In a real-effort lab experiment, Berger et al. [2013] compare unrestricted ranking of workers with a forced distribution system in which they have to be assigned different grades and find that productivity is significantly higher under the forced distribution.
} 
agents' efforts. As in Ertac et al. [2016], this makes the principal's payoff monotonic in agents' beliefs, which constitutes a crucial difference from our work. To reiterate, this is important because the team technology may render the principal's payoff non-monotonic and feedback uninformative, which implies that it may play a role in determining the effect of feedback on performance. This is precisely the main issue addressed in our work.

Verifiable feedback mechanisms induce a strategic communication game that is known as a "disclosure" game in the literature. ${ }^{12}$ Therefore, our paper is also related to the literature that experimentally tests the predictions of disclosure games. Early work in this literature has studied disclosure in the context of markets or auctions where the sender's payoff is monotonic in the receiver's beliefs and hence full information revelation is the unique equilibrium outcome. Forsythe et al. [1989] find that full information revelation is achieved as subjects become more sophisticated with repeated play, while King and Wallin [1991] and Benndorf et al. [2015] find that full disclosure does not occur. Jin et al. [2015] find that receiver subjects do not interpret "no news" sufficiently negatively. Hagenbach and Perez-Richet [2017] test the predictions of the theoretical model in Hagenbach et al. [2014] by considering payoff structures for the sender that are not necessarily monotonic in the receiver's action. They find that less information is revealed in cyclic games, i.e., games in which there are sender types that want to masquerade as each other, as compared to acyclic games. This is similar to our finding that more information is revealed in the best-shot public feedback treatment as compared to the weakest-link public feedback treatment. Differently from these papers, we focus on not the informativeness of feedback but its effect on team performance. ${ }^{13}$

Our work is also related to the growing experimental literature on the motivational effects of truthful performance feedback in both organizational and educational settings. These papers vary in the type of feedback considered (e.g., absolute or relative), the experimental setting (lab or field), and the type of incentives (fixed, piece-rate, or tournament). The focus has usually been on future performance, while satisfaction and quitting behavior have been studied as well (Azmat and Iriberri [2016], Rosaz et al. [2016]). Overall, this literature has produced a diverse array of results. In the workplace field setting, Blanes i Vidal and Nossol [2011] and Bradler et al. [2016] find that rank feedback and recognition increases performance, while Barankay [2012] documents that removing rank feedback has a positive effect. In the lab, there have also been mixed results that tend to vary with the type of incentive scheme. While the majority of papers document positive effects with flat wages (e.g., Charness et al. [2014], Gill et al. [2017], Kuhnen and Tymula [2012]), evidence is more mixed with performance pay (see, among others, Charness et al. [2010], Eriksson et al. [2009], Gerhards and Siemer [2014]). In the educational context, Azmat and Iriberri [2010], Bandiera et al. [2015], and Tran and Zeckhauser [2012] find that providing feedback to students increases performance, while Azmat et al. [2016] and Goulas and Megalokonomou [2015] point to heterogeneity in the effects of relative performance feedback, depending on students' initial beliefs (in the former) and achievement levels (in the latter). Our major departure from this literature is that we consider strategic rather than truthful feedback, and focus on the role of team technology, targeting the question: "In what kind of team settings is relative performance feedback conducive to team performance?"

\footnotetext{
${ }^{12}$ We discuss the relevant theoretical literature in Section 5.

${ }^{13}$ Another notable design difference from most of the literature is that we elicit beliefs directly rather than only measuring effort or another strategic choice that may be driven by other factors in the decision environment. This allows us to clearly see how individuals use the feedback to update their beliefs.
} 


\section{The Model}

There are two agents, indexed by $i=1,2$, and a principal. For each agent $i$, a state of the world $\theta_{i}$ is realized and observed only by the principal. In our experimental design, this state corresponds to ability (or a past performance indicator) and is either "high" or "low", denoted by $h$ and $l$, respectively. We assume that states are independently distributed across agents and the probability of $h$ for agent $i$ is equal to $p_{i} \in(0,1)$. Let $\Theta=\{h, l\}^{2}$ be the set of all states and denote the (common) prior on $\Theta$ by $p$. We will also assume for simplicity of exposition that $h$ and $l$ are real numbers with $h>l>0$.

The individual performance (or output) of agent $i$, which we denote $q_{i}$, depends on his effort $e_{i} \geq 0$ and individual ability: $q_{i}=q_{i}\left(e_{i}, \theta_{i}\right)$. We assume that $q_{i}$ is strictly increasing in $e_{i}$ and $\theta_{i}$ and symmetric, i.e., $q_{1}\left(e_{1}, \theta_{1}\right)=q_{2}\left(e_{2}, \theta_{2}\right)$, whenever $e_{1}=e_{2}, \theta_{1}=\theta_{2}$. Payoff function of agent $i$ is given by

$$
u_{i}\left(e_{i}, \theta\right)=\left(\theta_{i}-\alpha \theta_{-i}\right) e_{i}-\frac{1}{2} e_{i}^{2}
$$

where $\alpha \in(0,1)$ and $-i$ is the index of the other agent. We also assume that $\theta_{i}-\alpha \theta_{-i}>0$ for all $\theta$, so that the agent's payoff is increasing in effort at zero effort level. In the experiment, $p_{i}=0.5, h=20$, $l=12, \alpha=0.5$, and

$$
q_{i}\left(e_{i}, \theta_{i}\right)= \begin{cases}5 e_{i}, & \theta_{i}=l \\ 10 e_{i}, & \theta_{i}=h\end{cases}
$$

The principal's payoff is equal to the overall performance of the team $v\left(q_{1}, q_{2}\right)$. We consider two specifications for team performance:

$$
\begin{aligned}
& v\left(q_{1}, q_{2}\right)=\min \left\{q_{1}, q_{2}\right\} \\
& v\left(q_{1}, q_{2}\right)=\max \left\{q_{1}, q_{2}\right\}
\end{aligned}
$$

The first specification corresponds to "the weakest-link" technology and the second to "the best-shot" technology.

The game is composed of the following stages:

Stage I Nature chooses $\theta_{1}$ and $\theta_{2}$ according to $p$;

Stage II Principal observes $\theta=\left(\theta_{1}, \theta_{2}\right)$;

Stage III Principal sends a message to the agents;

Stage IV Agents 1 and 2 observe the message and independently choose $e_{1}$ and $e_{2}$.

We assume that principal's messages are verifiable, i.e., she can withhold information but cannot lie. We consider two types of feedback: public and private. Depending upon the feedback and the team performance technology, the above description induces four different extensive form games with incomplete information: (1) Weakest-link public feedback; (2) Weakest-link private feedback; (3) Best-shot public feedback; (4) Best-shot private feedback. 


\section{Experimental Design}

The experiment is designed to create a setup with one principal and two agents, where the principal cares about the team performance and can decide whether or not to send informative messages to the agents. The experiment has a $3 \times 2$ factorial design where feedback technology and team performance technology are treatment variables. Feedback technology takes three forms: no feedback, private feedback, and public feedback. This is varied within-subject, with every subject going through all three feedback treatments. The team performance technology varies between-subject: A random half of the subjects participate in "weakest-link" (minimum) technology sessions and the other half in "best-shot" (maximum) technology sessions.

The experiment consists of 21 periods: 2 periods with no feedback, 9 periods with private feedback, and 9 periods with public feedback. In the no-feedback treatment, subjects do not receive any information regarding their types and choose an effort level on the basis of their prior beliefs regarding abilities. ${ }^{14}$ This is our baseline treatment and represents situations in which feedback is impossible or prohibited.

In the private-feedback treatment, the principal has the option to give feedback to each agent privately and independently. Principals can choose to give correct information to both agents, give (correct) information to only one of them, or choose not to give any information to any agent. Agents only see the message targeted to them. Each message contains either information about both agents' abilities or no information.

In the public-feedback treatment, the principal has to send the same message to both agents. Therefore, the principal has two options, giving (correct) information to both agents on both agents' abilities or giving no information to either agent.

In each period of the feedback treatments, the following sequence of events occurs:

1. The computer randomly assigns an ability level (high or low) to each agent, unobservable to the agents.

2. The principal observes the abilities of the two agents with whom she is matched with.

3. The principal sends a message to the agents, which either contains correct information about both abilities or no information.

4. The principal is asked to guess agents' beliefs about the four states: $h h, h l, l h$, and $l l$.

5. Agents observe the principal's message. If an agent receives no information, he knows that this was the conscious choice of the principal.

6. Agents are asked to state their beliefs on the four states, $h h, h l, l h$, and $l l$.

7. Agents choose an effort level.

In the no-feedback treatment, the above sequence holds except that the principal cannot send messages. While we start with the baseline no-feedback treatment in all sessions, the order of the other within-subject treatments (private vs. public feedback) is randomized to eliminate potential order

\footnotetext{
${ }^{14}$ Subjects know that information is automatically withheld, i.e., the principal has no role in the feedback decision.
} 
effects. In order to prevent potential wealth effects, 3 out of 21 periods are randomly chosen after the experiment ends and subjects are paid according to their total payoff in these periods.

At the beginning of each period, each subject is randomly assigned to the role of either principal or agent. These roles change throughout the experiment in order for every subject to decide at least once as a principal and once as an agent. ${ }^{15}$ In addition, we use a "strangers" matching protocol where new 3-person groups, each of which consists of one principal and two agents, are randomly formed in every period. In each period, principals have an endowment of $120 \mathrm{ECU}$, and agents have an endowment of $100 \mathrm{ECU} .{ }^{16}$ If there are any losses in a period, they are deducted from this endowment. Subjects do not observe their payoffs until the end of the experiment. Verbatim instructions are given in Appendix B.

\subsection{Belief Elicitation}

In order to elicit the beliefs of the agents on the four possible states $(h h, h l, l h$, and $l l)$, we use a crossover mechanism developed independently by Karni [2009] and Mobius et al. [2014]. This is a Becker-De Groot-Marschak-type procedure designed to elicit beliefs truthfully and independently of risk preferences. In this method, subjects are presented with two lotteries that determine their payoff. One lottery is based on the true state (the true ability combination) and pays off 10 ECU if the state in question is the true state and zero payoff otherwise. The other lottery is based on chance and pays off 10 ECU with probability X, regardless of the abilities. Subjects are asked to report the minimum probability of winning in the chance-based lottery that would make them choose the chance-based lottery as opposed to the state-based lottery. Computer then draws X randomly and if it is at least as large as the minimum stated by the agent, the chance lottery applies. Otherwise, the agent is rewarded based on the actual state. In order to maintain incentive compatibility, one of the four states is selected randomly, and either the state-based lottery or the chance-based lottery is implemented to determine the subject's payoff. With this mechanism, it is optimal for the agents to report their true beliefs on each state as the minimum probability of winning threshold. This is explained to the subjects in detail in the instructions.

\subsection{Payoffs}

Agents' payoff from their effort choice is determined by equation (1), where $\theta_{i} \in\{12,20\}$ and $\alpha=0.5$. Note that, in accordance with our theoretical model, the marginal benefit of each agent's effort is increasing in his own ability and decreasing in the other agent's ability. The marginal benefit of effort depends on the abilities as in Table 1. Based on this, the potential payoffs that would be received in each state $(h h, h l, l h$ and $l l)$ for each effort level they might choose is provided as a table to the subjects during the experiment (see Table 13 in Appendix B). Agents' payoff from the belief elicitation stage, as described in section 4.1, is added to the payoff from effort.

Principals' payoff depends on the performances of the two agents as well as their own guesses about the agents' beliefs. Payoff from the performances, $q_{1}$ and $q_{2}$, is either given by (3) or (4) and $q_{i}$ is determined as in equation (2). Each principal makes eight guesses in each period, four for each

\footnotetext{
${ }^{15}$ Matching is optimized so that in each 9-period treatment, each subject has the role of principal in 3 periods, and the role of agent in 6 periods. In order to achieve this, total number of subjects in each session was chosen to be a multiple of 3 .

${ }^{16} 1$ ECU corresponded to 0.03 Turkish Liras at the time of the experiment.
} 
Table 1: Marginal Benefit of Effort

\begin{tabular}{lll}
\hline & \multicolumn{2}{l}{ Other's ability } \\
\cline { 2 - 3 } Own ability & High & Low \\
\hline High & 10 & 14 \\
Low & 2 & 6 \\
\hline
\end{tabular}

agent's beliefs. One of the eight guesses is selected randomly and she earns 10 ECU if her guess is in the \pm 0.05 range of the agent's stated beliefs.

\subsection{Risk Preference Elicitation}

Risk preferences might have an effect on both the agents' and the principals' behavior; for example, choosing a high effort level induces a riskier lottery in the sense of losses in case own ability is low. In order to control for risk attitudes, we elicit risk preferences of each subject at the end of the experiment using a version of the Holt-Laury task (Holt and Laury [2002]). Subjects are presented with a series of choices between riskier and safer lotteries as shown in Table 14 in Appendix B and the number of safe choices is taken as a measure of risk aversion.

\subsection{Procedures}

The experiment was programmed using the z-Tree software Fischbacher [2007] and implemented at the Koç University Behavioral Lab. We collected data from 165 participants, 83 male and 82 female. 13 sessions were held and each session lasted for about 75 minutes. At the end of each session we also conducted a survey to collect demographic data such as age, gender, major and GPA.

\section{Theory and Predictions}

There are four treatments in which the principal has the ability to provide feedback: (1) Weakestlink public feedback; (2) Weakest-link private feedback; (3) Best-shot public feedback; (4) Best-shot private feedback. Each one of these treatments induces a game of strategic communication, which is known in the literature as a "disclosure game." The basic models and the main results in this literature were introduced by Grossman [1981] and Milgrom [1981], which have later been extended in several directions. ${ }^{17}$ In particular, Koessler [2008] analyzes public and private communication in a model with two-receivers, two-states, and two-actions. Our model is significantly different from his because both the state and the action spaces are multidimensional and the payoff functions are different.

In the treatments with public feedback, the principal can either report $\theta$ truthfully to both agents or give no information. Therefore, a pure strategy of the principal is given by the function $\rho(\theta) \in\{\theta, n\}$ where $n$ denotes no-information. ${ }^{18}$ Belief function of agent $i$ is given by $\mu_{i}: \Theta \cup\{n\} \rightarrow \Delta(\Theta)$. Let

\footnotetext{
${ }^{17}$ See, for example, Seidmann and Winter [1997], Mathis [2008], Giovannoni and Seidmann [2007], and Hagenbach et al. [2014].

${ }^{18}$ We are assuming that giving information about only one agent is not possible. Our main results about existence and non-existence of fully revealing equilibria would go through with reacher message spaces. The message space that we have
} 
$\left(e_{1}^{*}\left(\mu_{1}\right), e_{2}^{*}\left(\mu_{2}\right)\right)$ be equilibrium effort choices at beliefs $\left(\mu_{1}, \mu_{2}\right)$ and $\rho^{-1}$ denote the inverse image of $\rho$. For any $E \subseteq \Theta$, let $p_{\mid E}$ denote the conditional probability distribution derived from the prior $p$ given that $\theta \in E$.

We will analyze the perfect Bayesian equilibrium of the resulting public-feedback game, which we define as follows:

Definition 1 (Public-Feedback Equilibrium). A (pure strategy) public-feedback equilibrium is an assessment $(\rho, \mu)$ such that for all $i \in\{1,2\}, \theta \in \Theta$, and $r \in\{\theta, n\}$

$$
\begin{aligned}
v\left(q_{1}\left(e_{1}^{*}\left(\mu_{1}(\rho(\theta))\right), \theta_{1}\right), q_{2}\left(e_{2}^{*}\left(\mu_{2}(\rho(\theta))\right), \theta_{2}\right)\right) & \geq v\left(q_{1}\left(e_{1}^{*}\left(\mu_{1}(r)\right), \theta_{1}\right), q_{2}\left(e_{2}^{*}\left(\mu_{2}(r)\right), \theta_{2}\right)\right) \\
\mu_{i}(\theta) & =\theta \\
\mu_{i}(n)=p_{\mid \rho^{-1}(n)}, & \text { if } \rho^{-1}(n) \neq \varnothing \\
\mu_{1}(n) & =\mu_{2}(n)
\end{aligned}
$$

Condition (5) is the sequential rationality condition for the principal and conditions (6) and (7) follow from Bayes' rule. We also require that agents' beliefs are consistent with each other even offthe-equilibrium path, which is condition (8). This follows from the strong Bayes' rule defined in Fudenberg and Tirole (1991) and would also be the case in any sequential equilibrium (Kreps and Wilson (1982)). ${ }^{19}$

If feedback is private, then the principal chooses to report the true $\theta$ or nothing to each agent independently, i.e., may choose to report $\theta$ to one agent and nothing to the other. A pure strategy of the principal is given by a pair of functions $\rho=\left(\rho_{1}, \rho_{2}\right)$ where $\rho_{i}(\theta) \in\{\theta, n\}$ for any $\theta \in \Theta$ and $i \in\{1,2\} .{ }^{20}$ Differently from the public feedback, she can report differently to each agent and induce different beliefs.

The following defines the perfect Bayesian equilibrium of the resulting private-feedback game.

Definition 2 (Private-Feedback Equilibrium). A (pure strategy) private-feedback equilibrium is an assessment $(\rho, \mu)$ such that for all $i \in\{1,2\}, \theta \in \Theta$, and $r_{i} \in\{\theta, n\}$

$$
\begin{gathered}
v\left(q_{1}\left(e_{1}^{*}\left(\mu_{1}\left(\rho_{1}(\theta)\right)\right), \theta_{1}\right), q_{2}\left(e_{2}^{*}\left(\mu_{2}\left(\rho_{2}(\theta)\right)\right), \theta_{2}\right)\right) \geq v\left(q_{1}\left(e_{1}^{*}\left(\mu_{1}\left(r_{1}\right)\right), \theta_{1}\right), q_{2}\left(e_{2}^{*}\left(\mu_{2}\left(r_{2}\right)\right), \theta_{2}\right)\right) \\
\mu_{i}(\theta)=\theta \\
\mu_{i}(n)=p_{\mid \rho_{i}^{-1}(n)}, \text { if } \rho_{i}^{-1}(n) \neq \varnothing
\end{gathered}
$$

Condition (9) is the sequential rationality condition for the principal and conditions (10) and (11) follow from Bayes' Rule.

Before we analyze the equilibria of the different games, we will state a common result about equilibrium effort. Optimal effort for an agent depends on his beliefs regarding the agents' abilities. Since marginal benefit of effort is increasing in own ability and decreasing in the other agent's ability, equilibrium effort is an increasing function of beliefs in a sense that we will make precise in what follows.

\footnotetext{
specified is the simplest one that provides what Hagenbach et al. [2014] calls an evidence base, i.e., every type has access to a message that certifies a set of types for which it is the worst case type.

${ }^{19}$ A similar point is emphasized in Koessler [2008].

${ }^{20}$ An alternative specification would be $\rho_{i}(\theta) \in\left\{\theta, n,\left(\theta_{i}, n\right),\left(n, \theta_{-i}\right)\right\}$. Our main results would go through with this alternative specification.
} 
Define the strict linear orders $\left(>_{1},>_{2}\right)$ on $\Theta$ as follows:

$$
\begin{aligned}
& (h, l)>_{1}(h, h)>_{1}(l, l)>_{1}(l, h) \\
& (l, h)>_{2}(h, h)>_{2}(l, l)>_{2}(h, l)
\end{aligned}
$$

A function $f: \Theta \rightarrow \mathbb{R}$ is strictly increasing in $>_{i}$ if $\theta>_{i} \theta^{\prime}$ implies $f(\theta)>f\left(\theta^{\prime}\right)$.

Definition 3 (First Order Stochastic Dominance). We say that $\mu \in \Delta(\Theta)$ strictly dominates $\mu^{\prime} \in \Delta(\Theta)$ for $i \in\{1,2\}$ (in the first order stochastic dominance sense) and write $\mu>_{i} \mu^{\prime}$ if for any function $f$ that is strictly increasing in $>_{i}$, the following is true:

$$
\sum_{\theta \in \Theta} f(\theta) \mu(\theta)>\sum_{\theta \in \Theta} f(\theta) \mu^{\prime}(\theta)
$$

We say that a function $f: \Delta(\Theta) \rightarrow \mathbb{R}$ is strictly increasing for $i \in\{1,2\}$, if $\mu>_{i} \mu^{\prime}$ implies $f(\mu)>f\left(\mu^{\prime}\right)$. Proposition 1. In any equilibrium, the effort choice of each agent is strictly increasing in his beliefs.

Proof of Proposition 1. In any equilibrium, effort choice must maximize expected payoff given beliefs:

$$
e_{i}^{*}\left(\mu_{i}\right) \in \underset{e_{i} \geq 0}{\operatorname{argmax}} \mathrm{E}_{\mu_{i}}\left[\left(\theta_{i}-\alpha \theta_{-i}\right)\right] e_{i}-\frac{1}{2} e_{i}^{2} .
$$

Since the objective function at $e_{i}=0$ is strictly increasing, the solution is in the interior, which implies the following first order condition:

$$
e_{i}^{*}\left(\mu_{i}\right)=\mathrm{E}_{\mu_{i}}\left[\theta_{i}\right]-\alpha \mathrm{E}_{\mu_{i}}\left[\theta_{-i}\right]
$$

This proves that $\mu_{i}>_{i} \mu_{i}^{\prime}$ implies $e_{i}^{*}\left(\mu_{i}\right)>e_{i}^{*}\left(\mu_{i}^{\prime}\right)$.

Together with $\alpha \in(0,1)$, this leads to our first empirical prediction:

Prediction A. In all treatments:

1. Effort increases in beliefs.

2. The effect of own ability on effort is greater than the effect of the other agent's ability.

Remark 1. This result assumes that agents are risk-neutral. This assumption is supported by the analysis of the experimental data, which reveals that risk-aversion does not play a significant role in effort choice. (See regression results reported in Table 2 in Section 6.1.) Furthermore, it can be shown that Proposition 1 would go through as long as the agents are not too risk-averse. Also, the specific (monetary) payoff function for the agents is not necessary for our main results. We only need the equilibrium effort to be increasing in beliefs, i.e., Proposition 1 to be true. Functional forms used in the experiment further help select some equilibria and make precise predictions regarding team performances.

\subsection{Weakest-Link Technology}

The payoff of the principal is given by equation (3). We analyze public and private feedback cases separately first and then compare them at the end of this section. 


\subsubsection{Public Feedback}

We first show that, in any equilibrium, the principal gives no feedback if only one of the agents has high ability.

Lemma 1. In any equilibrium, $\rho(l, h)=\rho(h, l)=n$.

Proof. All proofs from here on are relegated to Appendix A.

So, when the principal receives bad news, i.e., one of the agents has low ability, she reports no information. In the literature, there are two main reasons for the failure of full disclosure: (1) the payoff functions of the players who send messages fail some sort of "monotonicity" condition; (2) there are costs or frictions in the disclosure process. The reason why there is no full disclosure in our model falls into the first category: the principal is better off making the agents believe that $\theta=(l, h)$ when in fact $\theta=(h, l)$ rather than telling the truth, and vice versa. The reason is that when the team performance is determined by the worst performer, it is better to induce the worst beliefs on the high ability agent than on the low ability agent. ${ }^{21}$

Equilibrium behavior of types $(h, h)$ and $(l, l)$ depend on the prior distribution $p$ and the equilibrium effort functions. In our case, the equilibrium effort function is given by (13). If we further assume that the types are independently and identically distributed, then $e_{i}^{*}(h, h)>e_{i}^{*}(p)$ and $e_{i}^{*}(h, h)>e_{i}^{*}\left(p_{\{\{l, h),(h, l)\}}\right)$, which imply that $\rho(h, h)=(h, h)$, and $e_{i}^{*}\left(p_{\mid\{(l, h),(h, l)\}}\right)>e_{i}^{*}(l, l)$, which implies that $\rho(l, l)=n$. In other words, the principal provides information only when both agents have high ability.

Proposition 2. There is a unique equilibrium strategy profile: $\rho(h, h)=(h, h)$ and $\rho(\theta)=n$ for all $\theta \neq(h, h)$.

We may now answer one of the main questions that motivated our research. Which feedback regime is better for (the weakest-link) team performance? A public feedback mechanism or no feedback mechanism at all? Proposition 2 implies that when both agents have high ability, equilibrium team performance is $q_{1}\left(e_{i}^{*}(h, h), h\right)$, which is greater than the performance when feedback is not possible: $q_{1}\left(e_{i}^{*}(p), h\right)$. In all other cases, the no-feedback regime is better.

Equilibrium ex-ante team performance is equal to

$$
Q_{p}^{\text {min }}=\frac{1}{4} q_{1}\left(e_{1}^{*}(h, h), h\right)+\frac{3}{4} q_{1}\left(e_{i}^{*}\left(p_{\{\{(l, h),(h, l),(l, l)\}}\right), l\right)
$$

while ex-ante team performance under the no-feedback regime is equal to

$$
Q_{n}^{\min }=\frac{1}{4} q_{1}\left(e_{1}^{*}(p), h\right)+\frac{3}{4} q_{1}\left(e_{i}^{*}(p), l\right) .
$$

The difference in performance under no-feedback and public-feedback regimes is equal to

$$
Q_{n}^{\text {min }}-Q_{p}^{\text {min }}=\frac{1}{4}\left[q_{1}\left(e_{1}^{*}(p), h\right)-q_{1}\left(e_{1}^{*}(h, h), h\right)\right]+\frac{3}{4}\left[q_{1}\left(e_{i}^{*}(p), l\right)-q_{1}\left(e_{i}^{*}\left(p_{\mid\{(l, h),(h, l),(l, l)\}}\right), l\right)\right] .
$$

\footnotetext{
${ }^{21}$ In the terminology of Hagenbach et al. [2014], within the set of types that can send the message $n$, there is no worst case type, from which non-existence of a fully informative equilibrium follows. See also Seidmann and Winter [1997].
} 
The first term in the parenthesis is negative while the second is positive. The net effect depends on the parameters of the model. ${ }^{22}$

We have the following set of predictions:

Prediction B. In the weakest-link public-feedback treatment:

1. The principal provides information if both agents have high ability; otherwise, she provides no information.

2. Upon receiving no information, agents' beliefs decrease on $(h, h)$ and increase on other states.

3. Public-feedback regime is better for team performance than no-feedback regime if both agents have high ability. Otherwise, it is worse than no-feedback regime.

4. Public-feedback regime may be better or worse than no-feedback regime in terms of ex-ante team performance.

\subsubsection{Private Feedback}

We first show that in any fully informative equilibrium, no feedback is interpreted in the most pessimistic way by each agent.

Lemma 2. If in equilibrium $\rho_{i}(\theta) \neq \rho_{i}\left(\theta^{\prime}\right)$ for any $\theta \neq \theta^{\prime}$ and $i=1,2$, then $\mu_{1}(n)=(l, h)$ and $\mu_{2}(n)=$ $(h, l)$.

The reason is simple. Suppose that the equilibrium is fully informative and the state is $(l, h)$. Weakest-link technology and equilibrium effort function imply that this is the worst case scenario for team performance. If the beliefs of agent 1 following no information were to be different from this worst case scenario, then type $(l, h)$ would rather choose to provide no information to agent 1 and increase her payoff, contradicting sequential rationality and the hypothesis that the equilibrium is fully informative.

Consider the following assessment: For any $i=1,2$ and $\theta \in \Theta$

$$
\rho_{i}(\theta)=\theta ; \mu_{i}(\theta)=\theta, \mu_{1}(n)=(l, h), \mu_{2}(n)=(h, l) .
$$

This assessment is fully informative and it is easy to show that it constitutes an equilibrium.

Proposition 3. There is a fully informative equilibrium.

Remember that Lemma 2 implies that in any fully informative equilibrium, beliefs following noinformation are fixed even if no-information is an out of equilibrium action. Therefore, the equilibrium specified in (14) is essentially unique among fully informative equilibria: Types $(l, l),(h, h)$ report truthfully and types $(l, h)$ and $(h, l)$ either report truthfully or give no feedback, which is always interpreted in the most pessimistic way by each agent. The contrast with the public feedback case arises from the ability to induce different beliefs in agents following a report of no-information. This

\footnotetext{
${ }^{22}$ If we use the parameters in the experiment together with uniform prior, then $Q_{n}^{\text {min }}=50$ and $Q_{p}^{\text {min }}=52.5$. We can show that, if $p_{i}$ is greater than a certain threshold, i.e., if agents are sufficiently self-confident, then $Q_{n}^{\text {min }}$ is greater than $Q_{p}^{\text {min }}$.
} 
allows us to find a worst case type following report $n$ for each agent: $(l, h)$ for agent 1 and $(h, l)$ for agent 2 .

The only other equilibrium is partially informative and has the same structure as the unique equilibrium in the public-feedback game: the principal provides information if both agents have high ability and no information otherwise.

Proposition 4. Equilibrium is either fully informative or partially informative. If it is partially informative, then $\rho_{i}(h, h)=(h, h), \rho_{i}(\theta)=n, \theta \neq(h, h)$, for $i=1,2$.

If the state is $(h, h)$, both the partial and full information equilibrium performances are equal to $q_{1}\left(e_{1}^{*}(h, h), h\right)$, while performance under the no-feedback regime is equal to $q_{1}\left(e_{1}^{*}(p), h\right)<q_{1}\left(e_{1}^{*}(h, h), h\right)$. Therefore, both fully and partially informative private feedback is better for team performance when both agents have high ability. Since $q_{1}\left(e_{1}^{*}(p), l\right)>q_{1}\left(e_{1}^{*}\left(p_{\mid\{(l, h),(h, l),(l, l)\}}\right), l\right)>q_{1}\left(e_{1}^{*}(l, l), l\right)>q_{1}\left(e_{1}^{*}(l, h), l\right)$, in all other cases, the no-feedback regime is better than partially informative private feedback, which is itself better than fully informative private feedback.

Ex-ante team performances under the partially and fully informative equilibria are, respectively, equal to

$$
\begin{aligned}
Q_{p}^{\text {min }} & =\frac{1}{4} q_{1}\left(e_{1}^{*}(h, h), h\right)+\frac{3}{4} q_{1}\left(e_{i}^{*}\left(p_{\mid\{(l, h),(h, l),(l, l)\}}\right), l\right) \\
Q_{f}^{\text {min }} & =\frac{1}{4} q_{1}\left(e_{1}^{*}(h, h), h\right)+\frac{1}{2} q_{1}\left(e_{1}^{*}(l, h), l\right)+\frac{1}{4} q_{1}\left(e_{1}^{*}(l, l), l\right) .
\end{aligned}
$$

If, on the other hand, feedback is not possible, ex-ante performance is equal to

$$
Q_{n}^{\min }=\frac{1}{4} q_{1}\left(e_{1}^{*}(p), h\right)+\frac{3}{4} q_{1}\left(e_{i}^{*}(p), l\right)
$$

which may be greater or less than $Q_{p}^{\min }$ and $Q_{f}^{\min }$. In other words, team performance under the no-feedback regime may be better or worse than that under the private feedback regime. ${ }^{23}$

We have the following set of predictions:

Prediction C. In the weakest-link private-feedback treatment:

1. The principal provides information if both agents have high ability; in all other states she may or may not provide information.

2. Upon receiving no information, agents' beliefs decrease on $(h, h)$ and increase on $(l, h)$. Beliefs on other states may increase or decrease.

3. Private-feedback regime is better for team performance than no-feedback regime if both agents have high ability. Otherwise, it is worse than no-feedback regime.

4. Private-feedback regime may be better or worse than no-feedback regime in terms of ex-ante team performance.

\footnotetext{
${ }^{23}$ As before, if we use the parameters in the experiment together with uniform prior, then no-feedback performance is $Q_{n}^{\text {min }}=50$ while partial information performance is $Q_{p}^{\text {min }}=52.5$. Full information performance is $Q_{f}^{\text {min }}=37.5$.
} 
Finally, we can compare public and private feedback. In the public-feedback game there is only a partial information equilibrium, while in the private-feedback game there is a fully informative equilibrium in addition to the same partial information equilibrium. Note that the difference in performance under partially and fully informative equilibria is given by

$$
Q_{p}^{\min }-Q_{f}^{\min }=\frac{3}{4} q_{1}\left(e_{i}^{*}\left(p_{\mid\{(l, h),(h, l),(l, l)\}}\right), l\right)-\left[\frac{1}{2} q_{1}\left(e_{1}^{*}(l, h), l\right)+\frac{1}{4} q_{1}\left(e_{1}^{*}(l, l), l\right)\right]>0 .
$$

Therefore, ex-ante team performance is better under partially informative equilibrium than that under fully informative equilibrium. We may conclude that

Prediction D. If technology is the weakest-link:

1. Private feedback is expected to be more informative than public feedback.

2. We expect team performance under public feedback to be better than that under private feedback, except when both agents have high ability, in which case we expect no difference.

\subsection{Best-Shot Technology}

Payoff of the principal is given by (4). Again, we analyze public and private feedback cases separately.

\subsubsection{Public Feedback}

We show that the unique equilibrium outcome is fully informative.

Proposition 5. There is a unique equilibrium outcome and it is fully informative.

The intuition behind this result is as follows. Best-shot technology and the equilibrium effort function imply that the best case scenarios are when one agent has high and the other has low ability. This implies that types $(h, l)$ and $(l, h)$ must reveal themselves. But then type $(h, h)$ would rather reveal itself than pool with $(l, l)$, which implies that equilibrium must be fully revealing.

Ex-ante team performances under the no-feedback regime and the public-feedback regimes are, respectively, equal to

$$
\begin{aligned}
Q_{n}^{\max } & =\frac{3}{4} q_{1}\left(e_{1}^{*}(p), h\right)+\frac{1}{4} q_{1}\left(e_{i}^{*}(p), l\right) \\
Q_{f}^{\max } & =\frac{1}{4} q_{1}\left(e_{1}^{*}(h, h), h\right)+\frac{1}{2} q_{1}\left(e_{1}^{*}(h, l), h\right)+\frac{1}{4} q_{1}\left(e_{i}^{*}(l, l), l\right) .
\end{aligned}
$$

Therefore, team performance improves under public-feedback compared with the no-feedback regime in all cases except when both agents have low abilities. Direction of change in ex-ante performance is ambiguous, but as long as the prior belief on own ability $p_{i}$ is not too large, ex-ante performance also improves under public-feedback. We have the following predictions:

Prediction E. In the best-shot public-feedback treatment:

1. The principal provides information if at least one agent has high ability. If both have low ability, she may or may not provide information.

2. Upon receiving no information, agents' beliefs increase on $(l, l)$ and decrease on other states. 
3. Public-feedback is worse for team performance than no-feedback regime only when both agents have low ability; in every other state it is better.

4. Public-feedback regime is better than no-feedback regime in terms of ex-ante team performance.

\subsubsection{Private Feedback}

We have the following result.

Proposition 6. In any equilibrium, the best type is always informed when only one agent has high ability and at least one of the agents is informed when both have high ability.

The reason why the best type must reveal itself is the same as in public feedback case, i.e., this is the best case scenario when the technology is of best-shot variety. As before, this implies that type $(h, h)$ must reveal itself to at least one of the agents rather than pooling with type $(l, l)$ in reporting to both agents.

Furthermore, it can be shown that the following fully informative assessment is an equilibrium:

$$
\rho_{i}(\theta)=\theta, \mu_{i}(\theta)=\theta, \forall \theta \in \Theta, \mu_{i}(n)=(l, l), i=1,2 .
$$

Therefore we have the following proposition.

Proposition 7. There is a fully informative equilibrium.

In contrast with public feedback case, it turns out that there are also partially informative equilibria if feedback is private. For example, the following is an equilibrium:

$$
\begin{aligned}
& \rho_{1}(\theta)=\theta, \text { for } \theta \in\{(h, l),(h, h),(l, l)(l, h)\} ; \\
& \rho_{2}(\theta)=\theta, \text { for } \theta \in\{(l, h),(h, l)\}, \rho_{2}(\theta)=n, \text { for } \theta \in\{(h, h),(l, l)\} ; \\
& \mu_{1}(\theta)=\theta, \forall \theta, \mu_{1}(n)=(l, l) ; \\
& \mu_{2}(\theta)=\theta, \forall \theta \in\{(l, h),(h, l)\}, \mu_{2}(n)=p_{\mid\{(h, h),(l, l)\}} .
\end{aligned}
$$

Note, however, that in this equilibrium the principal obtains a higher payoff than the one with full revelation. Types $(l, l)$ and $(h, h)$ pool and report nothing to agent 2 and hence $(l, l)$ is better off compared with reporting truthfully. Type $(h, h)$ is not worse off because of this, since she reports truthfully to agent 1.

In fact, no equilibrium can lead to a worse team performance than that in fully informative equilibrium. Proposition 6 implies that, in any equilibrium team performance is equal to $q_{1}\left(e_{1}^{*}(h, h), h\right)$ in state $(h, h)$ and $q_{1}\left(e_{1}^{*}(h, l), h\right)$ in states $(h, l)$ and $(l, h)$. When both agents have low ability, team performance is equal to $q_{1}\left(e_{1}^{*}(l, l), l\right)$ in a fully informative equilibrium. It cannot be smaller than $q_{1}\left(e_{1}^{*}(l, l), l\right)$ in any other equilibrium, because if it were, then the principal could simply tell the truth to one of the agents and increase her payoff. Furthermore, as long as the prior belief on own ability $p_{i}$ is not too large, ex-ante performance improves under private feedback compared with the no-feedback regime.

We have the following predictions:

Prediction F. In the best-shot private-feedback treatment: 
1. If only one agent has high ability, the principal provides information to the high ability agent but she may or may not provide information to the other agent. If both agents have high ability, the principal provides information to at least one agent. If both agents have low ability, principal may or may not provide information.

2. Upon receiving no information, agents' beliefs decrease on $(h, l)$. Beliefs on other states may increase or decrease.

3. Private-feedback is better for team performance than no-feedback regime if at least one agent has high ability. If equilibrium is fully informative, private-feedback regime is worse than nofeedback when both agents have low ability, while it may be better or worse if equilibrium is partially informative.

4. Private-feedback regime is better than no-feedback regime in terms of ex-ante team performance.

Finally, we can compare the public and private-feedback regimes. In public-feedback there is only fully informative equilibrium, while in private-feedback there is also a partially informative equilibrium. We can summarize our findings as follows.

Prediction G. If technology is the best-shot:

1. Public feedback is more informative than private feedback.

2. Team performance under private and public feedback is the same in each state except $(l, l)$. Team performance under private feedback is better or the same in comparison to public feedback, both in state $(l, l)$ and ex-ante.

Finally, since the unique public feedback equilibrium outcome is fully informative when the technology is the best-shot and partially informative when it is the weakest-link, we have the following prediction:

Prediction H. Public feedback is more informative under the best-shot technology than under the weakest-link technology.

Remark 2. We have assumed throughout that the optimal effort of each agent is decreasing in the other agent's ability. If the opposite were the case, then the worst case type would be $(l, l)$ for both the weakest-link and the best-shot technologies and, as a result, there would be a fully informative public feedback equilibrium for both technologies. ${ }^{24}$ In other words, team technology makes a significant difference in terms of theoretical predictions only in the scenario that we are studying.

\section{Results}

Our main question is whether productivity related feedback improves team performance or not and a related question is whether such feedback transmits truthful information to the team members. We are particularly interested in whether the team production technology and the form of feedback make a difference to the answers to these questions. Many of our predictions in Section 5 depend

\footnotetext{
${ }^{24}$ This follows from the results presented in Seidmann and Winter [1997] and Hagenbach et al. [2014].
} 
on how agents choose effort as a function of their beliefs and risk preferences. Therefore, we start by presenting our results on effort behavior. We then present results on the main question of the paper: the effect of different feedback regimes on team performance. We continue with an analysis of information transmission and finish with principals' feedback behavior.

\subsection{Effort Behavior}

Table 2 presents regression results on the impact of beliefs on effort choice. First of all, we see that, controlling for beliefs, risk preferences do not play a significant role in effort choice. This validates our theoretical analysis of effort behavior, which assumes risk-neutrality. Second, as column (1) shows, coefficients on beliefs on ability are ordered as HL, HH, LL, and LH, in terms their magnitudes. As expected, HL and HH have positive effects on effort while $\mathrm{LH}$ has a negative effect. ${ }^{25}$ Third, column (2) shows that own ability has a greater absolute effect on effort than does the other agent's ability (Wald test, $p=0.000$ ). We list these findings below.

Result 1 (Effort Behavior).

1. Risk prefences do not play a significant role in effort choice.

2. Effort increases in beliefs on own (high) ability and decreases in beliefs on the other agent's ability.

3. The effect of own ability on effort is greater than the effect of the other agent's ability.

Our assumption of risk-neutrality is validated and Prediction A is confirmed.

The regression equation without the risk aversion and session controls, whose effects are very small and insignificant, is given by

$$
e=5.6+7.9 \times H L+4.6 \times H H-3.7 \times L H \text {. }
$$

If the constant term in the effort function is zero, this is equivalent to the following effort function

$$
e=13.5 \times H L+10.2 \times H H+5.6 \times L L+1.9 \times L H .
$$

After substituting the numerical values for $\mathrm{H}, \mathrm{L}$ and $\alpha$, the effort function predicted by theory, equation (13), can be rewritten as

$$
e=14 \times H L+10 \times H H+6 \times L L+2 \times L H .
$$

Comparing equations (15) and (16), we see that the fit between the theoretical and the estimated effort functions is remarkably good. This shows that, on average and given their beliefs, agents behave exactly like a rational risk-neutral agent in their effort choice. This finding is interesting on its own and provides empirical support for our equilibrium analysis in Section 5.

\footnotetext{
${ }^{25}$ Throughout the analysis we use the following notation for agent's beliefs: HH: Agent's belief that he is high ability and the other agent is high ability. HL: Agent's belief that he is high ability and the other agent is low ability. LH: Agent's belief that he is low ability and the other agent is high ability. LL: Agent's belief that he is low ability and the other agent is low ability. H: Agent's belief that he is high ability. L: Agent's belief that he is low ability. otherH: Agent's belief that the other agent is high ability. otherL: Agent's belief that the other agent is low ability. HLLH: Agent's belief that either one of the agents is high ability and the other agent is low ability.
} 
Table 2: Impact of Beliefs on Effort

\begin{tabular}{|c|c|c|}
\hline & $\begin{array}{c}\text { (1) } \\
\text { Effort }\end{array}$ & $\begin{array}{c}\text { (2) } \\
\text { Effort }\end{array}$ \\
\hline HL & $\begin{array}{c}7.912^{* * *} \\
(0.15)\end{array}$ & \\
\hline $\mathrm{HH}$ & $\begin{array}{c}4.609^{* * *} \\
(0.15)\end{array}$ & \\
\hline $\mathrm{LH}$ & $\begin{array}{c}-3.742^{* * *} \\
(0.17)\end{array}$ & \\
\hline $\mathrm{H}$ & & $\begin{array}{c}8.124^{* * *} \\
(0.11)\end{array}$ \\
\hline otherH & & $\begin{array}{c}-3.496^{* * *} \\
(0.11)\end{array}$ \\
\hline Risk Aversion & $\begin{array}{l}-0.003 \\
(0.04)\end{array}$ & $\begin{array}{l}-0.003 \\
(0.04)\end{array}$ \\
\hline Constant & $\begin{array}{c}5.688^{* * *} \\
(0.31)\end{array}$ & $\begin{array}{c}5.567^{* * *} \\
(0.31)\end{array}$ \\
\hline Session Controls & Yes & Yes \\
\hline $\mathrm{N}$ & 2212 & 2212 \\
\hline$\chi^{2}$ & 6705.477 & 6691.204 \\
\hline
\end{tabular}

\subsection{Team Performance}

Figure 1(a) shows average team performance in different treatments, including the no-feedback regime, and Table 3 presents regressions on the effect of feedback regimes on team performance, for each performance technology. Column (1) of Table 3 shows that when the technology is weakest-link, public feedback is not significantly different from the no-feedback regime, but the private feedback regime is worse than the no-feedback regime. A Wald test for the equality of coefficients shows that public and private feedback are not different in terms of ex-ante team performance $(p=0.2616)$. Column (5) shows that when the team performance is of best-shot variety, both private and public feedback lead to better team performance than does no-feedback but they are not significantly different from each other $(p=0.9357)$.

As we have seen in Section 5, the effect of feedback on team performance might depend on the composition of the team. Team performances in different treatments for different team compositions are depicted in Figure 1 (b)-(d). Columns (2)-(4) of Table 3 show that if technology is weakestlink, public and private feedback are both better for team performance than no-feedback when both agents have high ability; otherwise, both feedback regimes are worse than no-feedback. In all cases, public feedback is better than private feedback, but the difference is not significant when both agents have high ability. ${ }^{26}$

Columns (6)-(8) show that if technology is best-shot and only one of the agents has high ability, then private feedback is better than public feedback ( $p=0.0863$ ), which is in turn better than nofeedback. Both types of feedback are worse than no feedback but they are not significantly different

\footnotetext{
${ }^{26}$ Wald test results for equality of coefficients are $p=0.1867, p=0.0623$, and $p=0.0023$, for columns (2), (3), and (4), respectively.
} 
(a)

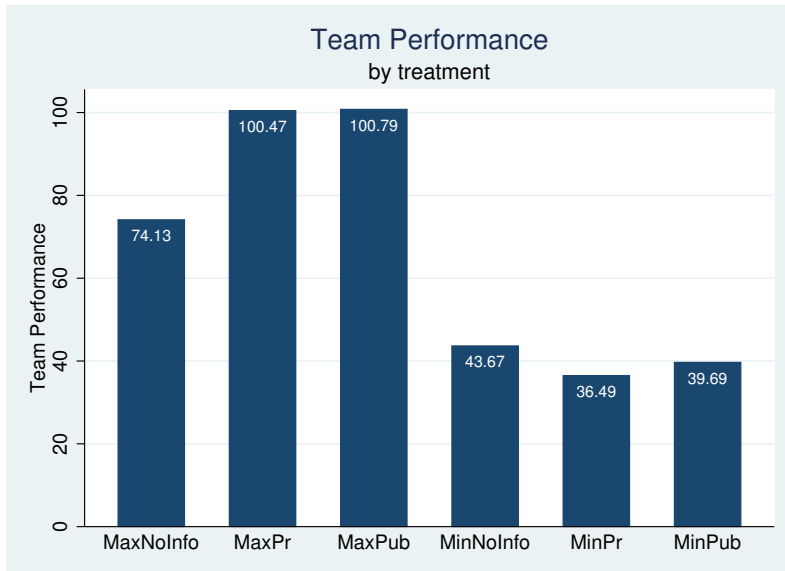

(c)

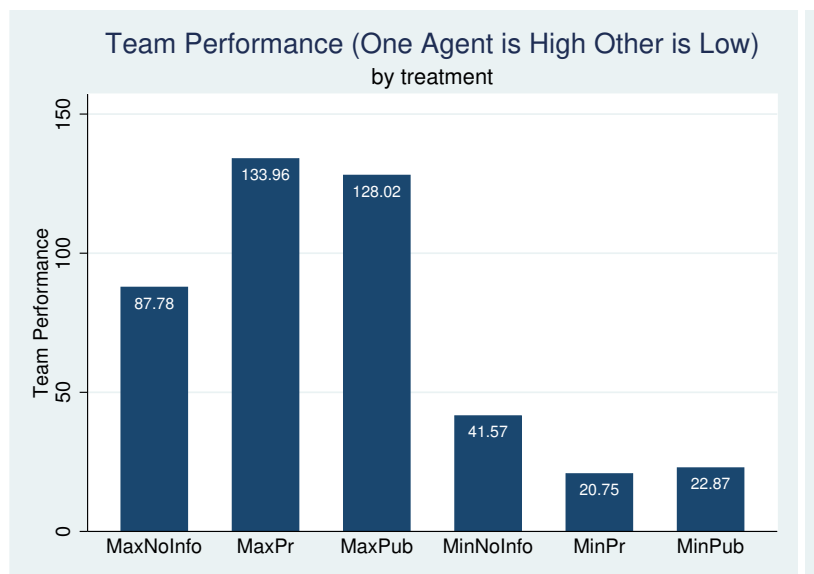

(b)

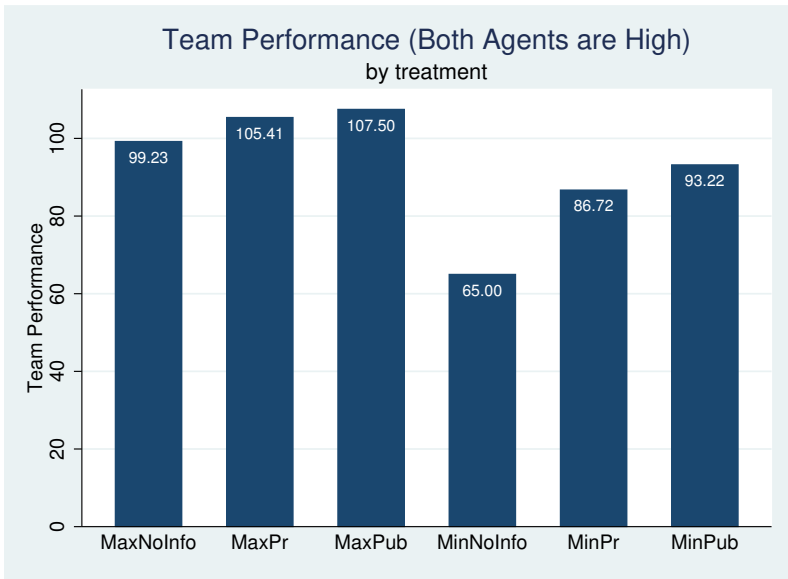

(d)

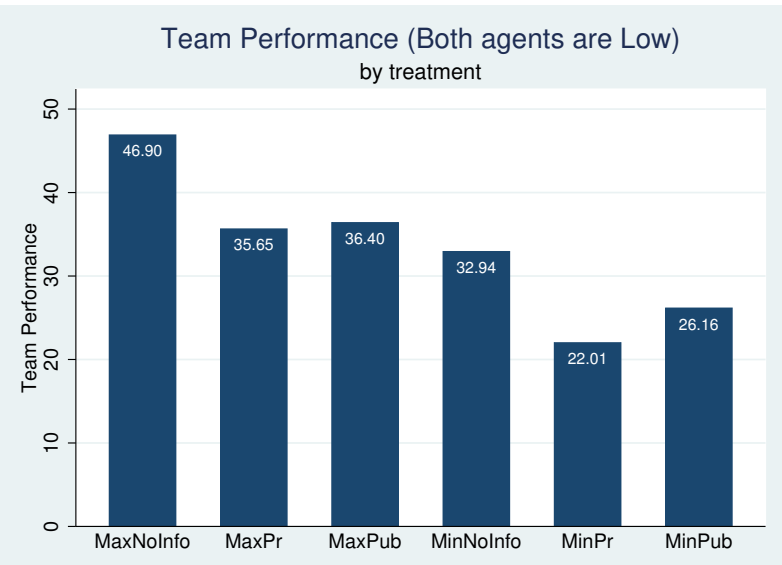

from each other when both agents have low ability ( $p=0.1134)$. If both agents have high ability, then public and private feedback are not significantly different from no feedback ( $p=0.1795$ and $p=0.2787$, respectively) or from each other $(p=0.6580)$.

Table 4 summarizes these findings and also presents the theoretical predictions for ease of comparison. The Data columns in Table 4 rank team performance in terms of absolute magnitudes and indicate statistical significance with stars. Mann-Whitney tests of differences between team performances under different feedback regimes produce similar results, except that public feedback is better than private feedback for ex-ante team performance with $p=0.0617$ when the technology is weakest-link, which we indicate with a star as well. As that table shows, overall, there is a good fit between the theoretical predictions and the data. Figure 2 compares the theoretically predicted team performance (2a) with actual values (2b). ${ }^{27}$ Again, there is a very close match between the two figures except for the weakest-link public-feedback treatment where the actual performance is smaller than the predicted one. This might be due to the fact that, in that treatment, principals reveal more

\footnotetext{
${ }^{27}$ In calculating the theoretical predictions, we used each agent's actual prior belief and assumed that the fully informative equilibrium is played in the maximum-private and minimum-private treatments. If we were to assume the partially informative equilibrium in the minimum-private treatment, the theoretical prediction would be 51.47 rather than 36.17. Since the latter is closer to the actual performance number, we may also conclude that the subjects' behavior is closer to the fully informative equilibrium behavior in that treatment.
} 
Table 3: Team Performance in Each Performance Technology, by Team Composition

\begin{tabular}{|c|c|c|c|c|c|c|c|c|}
\hline & \multicolumn{4}{|c|}{ Minimum } & \multicolumn{4}{|c|}{ Maximum } \\
\hline & (1) & (2) & (3) & (4) & (5) & (6) & (7) & (8) \\
\hline & Overall & Both High & One High other Low & Both Low & Overall & Both High & One High other Low & Both Low \\
\hline \multirow[t]{2}{*}{ Private } & $-7.528^{*}$ & $22.306^{* * *}$ & $-22.349^{* * *}$ & $-10.733^{* * *}$ & $26.208^{* * *}$ & 6.577 & $45.800^{* * *}$ & $-9.791^{* * *}$ \\
\hline & $(4.34)$ & $(6.51)$ & $(2.44)$ & $(2.28)$ & $(6.61)$ & $(6.07)$ & $(6.81)$ & $(2.95)$ \\
\hline \multirow[t]{2}{*}{ Public } & -4.328 & $27.151^{* * *}$ & $-19.392^{* * *}$ & $-6.353^{* * *}$ & $26.528^{* * *}$ & 8.218 & $40.242^{* * *}$ & $-9.480^{* * *}$ \\
\hline & $(4.34)$ & (6.55) & $(2.44)$ & (2.29) & $(6.61)$ & $(6.12)$ & (6.79) & $(2.97)$ \\
\hline \multirow[t]{2}{*}{ Risk Aversion } & 0.266 & 1.573 & 0.339 & 0.127 & 0.520 & 0.554 & -0.050 & 0.535 \\
\hline & $(0.89)$ & $(1.61)$ & $(0.66)$ & $(0.50)$ & (1.68) & (1.34) & (1.37) & $(0.82)$ \\
\hline Session Controls & Yes & Yes & Yes & Yes & Yes & Yes & Yes & Yes \\
\hline Constant & Yes & Yes & Yes & Yes & Yes & Yes & Yes & Yes \\
\hline $\mathrm{N}$ & 586 & 132 & 297 & 157 & 520 & 130 & 250 & 140 \\
\hline$\chi^{2}$ & 6.522 & 29.487 & 96.834 & 32.144 & 2160.975 & 3820.451 & 52.908 & 37.210 \\
\hline
\end{tabular}

Table 4: Team Performance: Theory vs. Data

\begin{tabular}{|l|c|c|c|c|}
\cline { 2 - 5 } \multicolumn{1}{c|}{} & \multicolumn{2}{c|}{ Weakest-Link } & \multicolumn{2}{c|}{ Best-Shot } \\
\cline { 2 - 5 } \multicolumn{1}{c|}{ Theory } & Data & Theory & Data \\
\hline ex-ante & pub $>$ priv & no $>$ pub $>^{*}$ priv & priv $\geq$ pub $>$ no & pub $>$ priv $>^{* * *}$ no \\
HH & pub $\approx$ priv $>$ no & pub $>$ priv $>^{* * *}$ no & priv $\approx$ pub $>$ no & pub $>$ priv $>$ no \\
HLLH & no $>$ pub $>$ priv & no $>^{* * *}$ pub $>^{*}$ priv & priv $\approx$ pub $>$ no & priv $>^{*}$ pub $>^{* * *}$ no \\
LL & no $>$ pub $>$ priv & no $>^{* * *}$ pub $>^{* * *}$ priv & priv $\geq$ pub, no $>$ pub & no $>^{* * *}$ pub $>$ priv \\
\hline
\end{tabular}

${ }^{*} p<0.10,{ }^{* *} p<0.05,{ }^{* * *} p<0.01$

information than predicted by theory, as we discuss in more detail in Section 6.4.

It is possible to summarize our main findings here as follows.

Result 2 (Team Performance).

1. If team performance is determined by the weakest-link, then no-feedback is the best regime unless the team is composed of all high performers, in which case public or private-feedback is better. Public feedback is always better than or equivalent to private feedback. Predictions B.3, C.3, and D. 2 are confirmed.

2. If team performance is determined by the best-shot, then both public and private-feedback are better than no-feedback unless the team is composed of all low performers, in which case nofeedback is best. There is no significant difference between public and private-feedback, except when the team is heterogenous, in which case private feedback is better. Predictions E.3, E.4, F.3, F.4 are confirmed. Prediction G. 2 receives partial support.

\subsection{Agents' Behavior}

\subsubsection{Prior Beliefs and Risk Preferences}

We first examine agents' beliefs when the possibility of giving feedback does not exist, i.e., in the nofeedback treatment. It is explicitly stated during the experiment that each agent will be independently assigned high and low types with equal probabilities by the computer. Therefore, agents are expected 
Figure 2: Team Performance: Theory vs. Data

(a) Predicted Team Performance

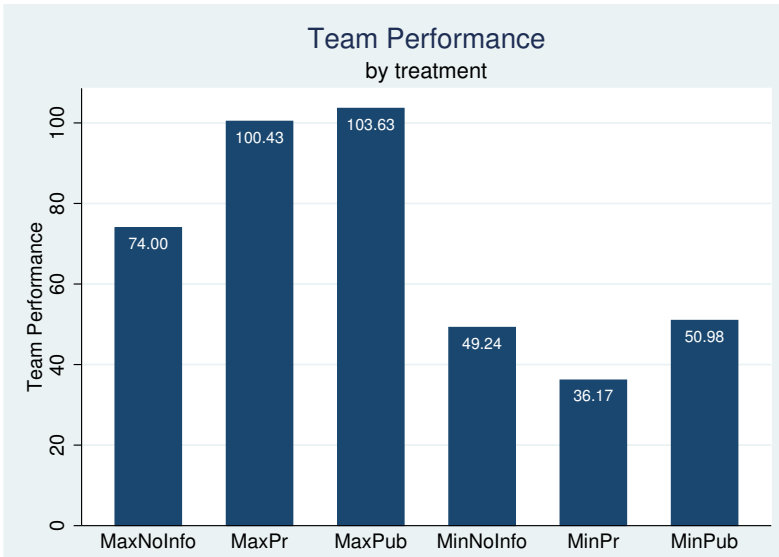

(b) Actual Team Performance

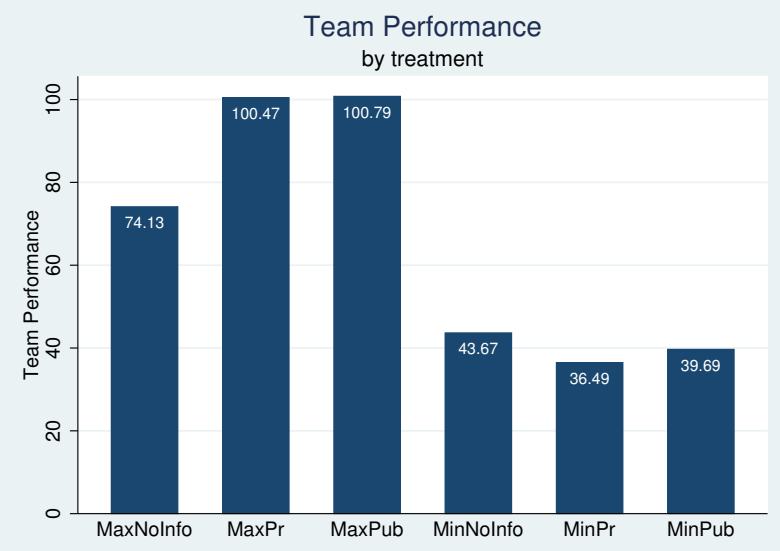

Table 5: Beliefs After Information

\begin{tabular}{lcccc}
\hline & HH & HL & LH & LL \\
\hline Maximum - Private & 0.94 & 0.97 & 0.95 & 0.95 \\
Maximum - Public & 0.94 & 0.98 & 0.94 & 0.90 \\
Minimum - Private & 0.91 & 0.92 & 0.93 & 0.91 \\
Minimum - Public & 0.92 & 0.97 & 0.90 & 0.93 \\
\hline
\end{tabular}

to attribute equal probabilities to the four states of the world: HL, HH, LL, LH. However, the average probabilities assigned to HL, HH, LL, and LH turn out to be $0.32,0.25,0.21$, and 0.22 . In other words, subjects overestimate the probability of having higher ability than the other agent, which is in line with the large literature in psychology and economics on overconfidence and overoptimism (e.g., Weinstein [1980]).

In the Holt-Laury risk elicitation task, subjects choose the safe lottery 5.86 times on average (out of 10 available choices), indicating that, on average, subjects are slightly risk averse.

\subsubsection{Feedback and Beliefs}

Any information provided by the principal has to be truthful, which implies that agents should put probability one on the reported state. Table 5 shows that, on average, beliefs, though not exactly equal to one, are very close to it. Statistical tests show that beliefs conditional on states are not statistically different from one in any treatment when the principal provides information. This shows that most of the subjects have understood the verifiable nature of the information provided.

Of course, the more interesting question is how agents change their beliefs when the principal provides no information. Figure 3 plots the change in beliefs in each treatment when the agents receive no information from the principal. Table 6 presents the effect of each treatment on the change in beliefs using regressions that control for risk preferences and session effects. We compare these empirical findings with theoretical predictions in Table 7, where an empty cell indicates that there is no precise theoretical prediction and stars indicate the level of statistical significance of the change. 


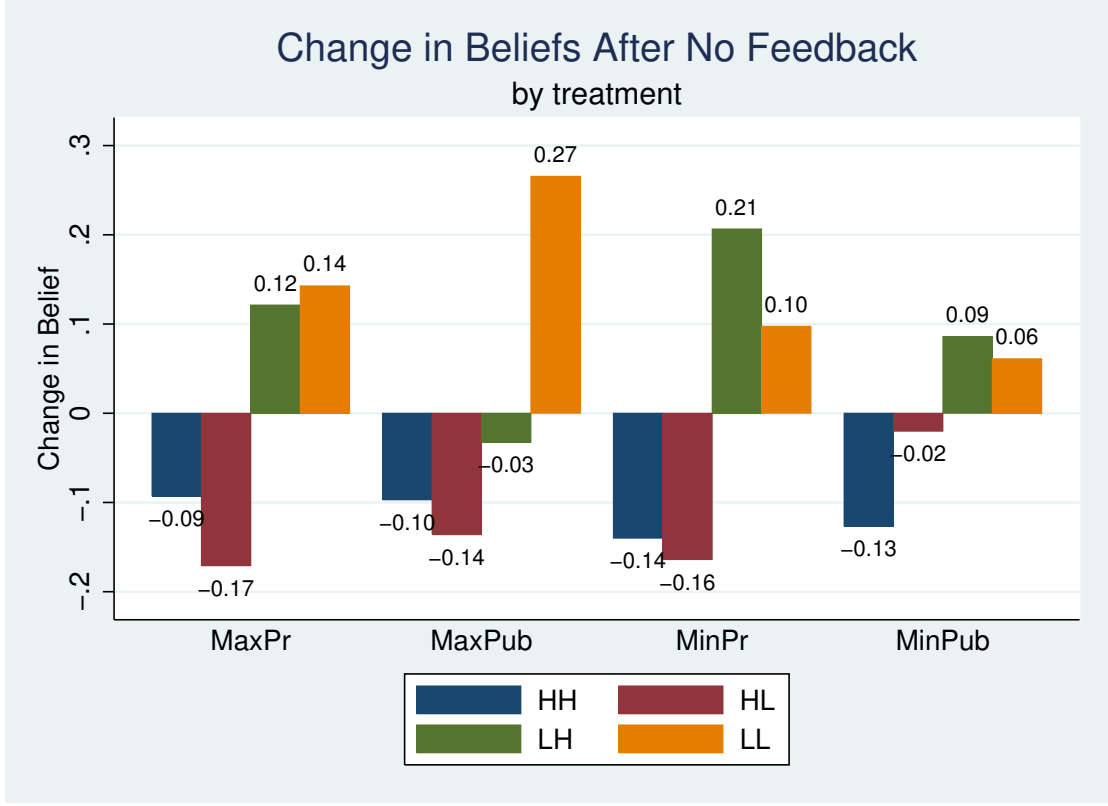

In terms of the precise predictions that the theory can make, the fit is perfect except for beliefs on HL in the minimum-public treatment, which is significant at $10 \%$ level. ${ }^{28}$

In the maximum-public treatment, the unique equilibrium outcome is fully informative and the data show that agents revise their beliefs exactly in accordance with equilibrium behavior: upon receiving no information they believe that both agents are low type. ${ }^{29}$

In the maximum-private treatment there is a fully-informative equilibrium as well as partially informative equilibria, which makes precise predictions regarding beliefs after no-information impossible. However, Proposition 6 shows that the best type is always informed and at least one of the agents is informed when both have high ability. Data show that, after no information, beliefs on both $\mathrm{HH}$ and HL decrease and the decrease in beliefs on HL is bigger, which is compatible with this result. We also see that beliefs on both LH and LL increase. It seems that when they receive no information from the principal, agents conclude that they have low ability and the least likely state is HL. ${ }^{30}$

In the minimum-public treatment, there is a unique equilibrium in which only $\mathrm{HH}$ reveals itself and the others provide no information. Data is consistent with this equilibrium except that there is a drop in beliefs on HL. Again, it seems that at least some agents interpret no information simply as being low type. ${ }^{31}$

In the minimum-private treatment, there is a fully-informative equilibrium in which each agent interprets no-information in the most pessimistic way, i.e., own ability is low and the other's ability is

\footnotetext{
${ }^{28}$ This drop is significant at $1 \%$ level when we control for period effects. This is the only major effect of controlling for period in the entire analysis. Regression analysis with period controls are available upon request.

${ }^{29}$ The changes in HH and HL beliefs are significantly negative, whereas the change in the LL belief is significantly positive. However, the change in the LH belief is not significantly different from zero $(p=0.3945)$.

${ }^{30}$ The changes in HH and HL beliefs are significantly negative. The change in HL beliefs is significantly larger than that in HH beliefs ( $p=0.0084$ ). The changes in LH and LL beliefs are significantly positive, however they are not significantly different from each other in a full regression model with interactions $(p=0.5134)$.

${ }^{31}$ The change in HH beliefs is significantly negative, while the changes in LH and LL beliefs are significantly positive. The change in beliefs on HL is significantly different from zero at the $10 \%$ level $(p=0.0964)$. Changes in LH and LL beliefs are not significantly different from each other in a full regression model with interactions ( $p=0.1059$ ).
} 
Table 6: Change in Beliefs After No Information

\begin{tabular}{lcccc}
\hline \hline & $(1)$ & $(2)$ & $(3)$ & $(4)$ \\
& $\mathrm{HH}$ & $\mathrm{HL}$ & $\mathrm{LH}$ & $\mathrm{LL}$ \\
\hline Maximum-Private & $-0.091^{* * *}$ & $-0.174^{* * *}$ & $0.129^{* * *}$ & $0.136^{* * *}$ \\
& $(0.02)$ & $(0.02)$ & $(0.02)$ & $(0.02)$ \\
Maximum-Public & $-0.105^{* * *}$ & $-0.145^{* * *}$ & -0.020 & $0.268^{* * *}$ \\
& $(0.02)$ & $(0.02)$ & $(0.02)$ & $(0.02)$ \\
Minimum-Private & $-0.144^{* * *}$ & $-0.166^{* * *}$ & $0.213^{* * *}$ & $0.098^{* * *}$ \\
& $(0.01)$ & $(0.02)$ & $(0.02)$ & $(0.02)$ \\
Minimum-Public & $-0.129^{* * *}$ & $-0.027^{*}$ & $0.095^{* * *}$ & $0.061^{* * *}$ \\
& $(0.01)$ & $(0.02)$ & $(0.02)$ & $(0.02)$ \\
Risk Aversion & -0.001 & -0.000 & 0.002 & -0.001 \\
& $(0.01)$ & $(0.01)$ & $(0.01)$ & $(0.01)$ \\
Session Controls & Yes & Yes & Yes & Yes \\
Constant & Yes & Yes & Yes & Yes \\
\hline $\mathrm{N}$ & 873 & 873 & 873 & 873 \\
$\chi^{2}$ & 180.039 & 254.630 & 222.855 & 190.412 \\
\hline \hline GLS Regressions, standard errors in parantheses. Baseline is no-information treatment. \\
${ }^{*}$ p $<0.10,{ }^{* *} \mathrm{p}<0.05,{ }^{* * *} \mathrm{p}<0.01$. & \multicolumn{3}{l}{}
\end{tabular}

Table 7: Change in Beliefs After No Information: Theory vs. Data

\begin{tabular}{|c|c|c|c|c|c|c|c|c|}
\hline & \multicolumn{4}{|c|}{ Theory } & \multicolumn{4}{|c|}{ Data } \\
\hline & $\mathrm{HH}$ & HL & LH & LL & $\mathrm{HH}$ & HL & LH & $\mathrm{LL}$ \\
\hline Maximum - Private & & - & & & $-{ }^{* * *}$ & $-{ }^{* * *}$ & $+{ }^{* * *}$ & $+* * *$ \\
\hline Maximum - Public & - & - & - & + & $-{ }^{* * *}$ & $-* * *$ & - & $+* * *$ \\
\hline Minimum - Private & - & & + & & $-* * *$ & $-* * *$ & $+* * *$ & $+* * *$ \\
\hline Minimum - Public & - & + & + & + & $-{ }^{* * *}$ & $-{ }^{*}$ & $+{ }^{* * *}$ & $+* * *$ \\
\hline
\end{tabular}


high, as well as a partially-informative equilibrium in which only type HH reveals itself. In either of these equilibria, beliefs on HH must decrease and those on LH must increase, which is exactly what the data show. Beliefs on other states depend on which equilibrium is played. If subjects play the fully informative equilibrium, we would expect beliefs on LL to decrease as well, which is not what the data show. If they play the partially informative equilibrium, we would expect beliefs on HL to increase, which is again not what the data show. ${ }^{32}$ There are three possibilities: (1) Agents are confused about which equilibrium behavior the principals exhibit, (2) different agents play different equilibria, or (3) the only inference they make from no-information is that their own type is low. The fact that the biggest change is the increase in beliefs on LH suggests that at least some agents believe they are in the fully informative equilibrium. However, the overall change in beliefs is also consistent with agents interpreting no-information simply as being low type.

Overall, we have the following result.

Result 3 (Beliefs). Agents in general revise their beliefs in accordance with our theoretical expectations stated in Predictions B.2, C.2, E.2, and F.2. The best fit occurs in the maximum-public treatment, which has a fully informative equilibrium. In other treatments, at least some agents interpret no-information simply as having low ability.

\subsubsection{Information Transmission}

We next analyze the informativeness of different feedback regimes in each technology. For this purpose, we create an information transmission variable as follows: if the actual state is $\theta$ and the agent puts probability $p$ on $\theta$, then information transmission is set equal to $p$. Our results in column (1) of Table 8 suggest that there is significant information transmission in every treatment, that is, beliefs conditional on actual states are significantly larger than those in no-information treatment.

Column (2) and (3) show that the team technology does not make a difference in terms of information transmission when feedback is private but public feedback is more informative when the technology is best-shot. Columns (4) and (5) show that there is more information transmission in the private-feedback regime when the technology is weakest-link and in public feedback when the technology is best-shot, which is what we have predicted. However, only the second effect is statistically significant at the $10 \%$ level. Therefore, we have the following result.

Result 4 (Information Transmission). There is significant information transmission in every treatment.

1. Public feedback is more informative than private feedback when the technology is best-shot. Prediction G.1 is confirmed.

2. Private feedback is more informative than public feedback when the technology is weakest-link, but the difference is not statistically significant. Prediction D.1 is only weakly supported.

3. Public feedback is more informative under the best-shot technology than under the weakest-link technology. Prediction H is confirmed.

\footnotetext{
${ }^{32}$ Change in beliefs on HH and HL are negative and those in LH and LL are positive with significance level of $p=0.000$. Changes in beliefs on HH and HL are not different from each other ( $p=0.2988)$, whereas the change in LH is significantly larger than the change in LL $(p=0.0000)$. Therefore, agents believe that they are more likely to have low ability while the other agent has high ability.
} 
Table 8: Information Transmission in Different Treatments

\begin{tabular}{|c|c|c|c|c|c|}
\hline & $\begin{array}{c}(1) \\
\text { Info-Transmission }\end{array}$ & $\begin{array}{c}(2) \\
\text { Info-Transmission } \\
\text { Private Feedback }\end{array}$ & $\begin{array}{c}(3) \\
\text { Info-Transmission } \\
\text { Public Feedback }\end{array}$ & $\begin{array}{c}(4) \\
\text { Info-Transmission } \\
\text { Minimum }\end{array}$ & $\begin{array}{c}(5) \\
\text { Info-Transmission } \\
\text { Maximum }\end{array}$ \\
\hline Maximum-Private & $\begin{array}{c}0.519^{* * *} \\
(0.03)\end{array}$ & & & & \\
\hline Maximum-Public & $\begin{array}{c}0.556^{* * *} \\
(0.03)\end{array}$ & & & & \\
\hline Minimum-Private & $\begin{array}{c}0.458^{* * *} \\
(0.03)\end{array}$ & & & & \\
\hline Minimum-Public & $\begin{array}{c}0.436^{* * *} \\
(0.03)\end{array}$ & & & & \\
\hline Maximum & & $\begin{array}{l}-0.082 \\
(0.06)\end{array}$ & $\begin{array}{c}0.205^{* * *} \\
(0.05)\end{array}$ & & \\
\hline Private & & & & $\begin{array}{l}0.023 \\
(0.02)\end{array}$ & $\begin{array}{c}-0.037^{*} \\
(0.02)\end{array}$ \\
\hline Risk Aversion & $\begin{array}{l}-0.004 \\
(0.01)\end{array}$ & $\begin{array}{l}0.003 \\
(0.01)\end{array}$ & $\begin{array}{l}-0.012 \\
(0.01)\end{array}$ & $\begin{array}{l}-0.011 \\
(0.01)\end{array}$ & $\begin{array}{l}0.005 \\
(0.01)\end{array}$ \\
\hline Session Controls & Yes & Yes & Yes & No & No \\
\hline Constant & Yes & Yes & Yes & Yes & Yes \\
\hline $\mathrm{N}$ & 2212 & 990 & 990 & 1044 & 936 \\
\hline$\chi^{2}$ & 555.111 & 39.207 & 62.680 & 33.957 & 11.922 \\
\hline
\end{tabular}

\subsection{Principals' Behavior}

We now turn to analyze principals' behavior. In the maximum-public treatment, theory predicts that the principal provides information when at least one of the agents has high ability, while she may or may not provide information when both have low ability. Table 9 shows that almost all the principals behave in a consistent manner with this prediction (91\% in HH and $84 \%$ in HL or LH). Column (2) of Table 10 reports the results of a logit regression where the dependent variable is equal to 1 if principal provides feedback and 0 otherwise. The results are again consistent with theory: the only state where principals are (significantly) less likely to reveal information is when both agents have low ability. Note that we have previously established that agents revise beliefs after no information in exact accordance with this strategy: They increase their beliefs on LL and decrease them on all the other states.

In the minimum-public treatment, theory predicts that the principal provides information only when both agents have high ability. Table 9 shows that while most principals send information when both agents have high ability ( $88 \%$ ), they also tend to do so in other states as well (58\% in HL or LH and $32 \%$ in LL). Column (1) of Table 10 shows that principals are indeed less likely to send information when at least one of the agents has low ability and this effect is stronger when only one has low ability, which is consistent with our theoretical predictions. However, principals seem to provide more information than predicted in this treatment. As we have mentioned before, this seems to be the reason why actual team performance is worse than what the theory predicts (see Figure 2).

In the maximum-private treatment, theory suggests that the principal provides information to the best agent and to at least one agent when both have high ability. Table 11 shows that the overwhelming majority of the principals act accordingly (95\% in HH, 90\% in HL, and 100\% in LH). Column 2 of Table 12 shows that the principal is more likely to send information to the high ability agent when the 
Table 9: Feedback to Both Agents in Public Feedback

\begin{tabular}{ccc|cc}
\hline \hline & \multicolumn{2}{c|}{ Minimum-Public } & \multicolumn{2}{c}{ Maximum-Public } \\
Actual & Info & No Info & Info & No Info \\
\hline HH & 52 & 7 & 51 & 5 \\
& $(88.14)$ & $(11.86)$ & $(91.07)$ & $(8.93)$ \\
HL or LH & 54 & 75 & 102 & 19 \\
& $(41.86)$ & $(58.14)$ & $(84.30)$ & $(15.70)$ \\
LL & 50 & 23 & 31 & 26 \\
& $(68.49)$ & $(31.51)$ & $(54.39)$ & $(45.61)$ \\
\hline
\end{tabular}

Number of agents receiving each message type, percentages in parentheses.

The abbreviations in message part represents message pairs.

$\mathrm{H}=$ High ability $\mathrm{L}=$ Low ability $\mathrm{No}=$ No message.

Table 10: Principal's Strategy in Public Feedback

\begin{tabular}{lcc}
\hline \hline & $(1)$ & $(2)$ \\
& Public Feedback (Minimum) & Public Feedback (Maximum) \\
\hline One agent is low, the other is high & $-0.474^{* * *}$ & -0.098 \\
& $(0.09)$ & $(0.08)$ \\
Both Agents are low & $-0.236^{* *}$ & $-0.327^{* * *}$ \\
& $(0.11)$ & $(0.08)$ \\
Risk Aversion & 0.006 & 0.010 \\
& $(0.02)$ & $(0.02)$ \\
Session Controls & Yes & Yes \\
\hline $\mathrm{N}$ & 261 & 234 \\
\hline \hline
\end{tabular}

Logit Regressions, marginal effects. Standard error in parantheses. Errors are clustered across observations. Dependent variable is public feedback. It takes value of 1 if principal provides public feedback, 0 otherwise. ${ }^{*} \mathrm{p}<0.10,{ }^{* *} \mathrm{p}<0.05,{ }^{* * *} \mathrm{p}<0.01$ 
Table 11: Feedback to Both Agents in Private Feedback

\begin{tabular}{|c|c|c|c|c|c|c|c|c|}
\hline \multirow[b]{2}{*}{ Actual } & \multicolumn{4}{|c|}{ Minimum-Private } & \multicolumn{4}{|c|}{ Maximum-Private } \\
\hline & Both Info & Info, No Info & No Info, Info & Both No Info & Both Info & Info, No Info & No Info, Info & Both No Info \\
\hline \multirow[t]{2}{*}{$\mathrm{HH}$} & 48 & 2 & 3 & 8 & 41 & 12 & 5 & 3 \\
\hline & (78.69) & (3.28) & $(4.92)$ & (13.11) & $(67.21)$ & (19.67) & $(8.20)$ & $(4.92)$ \\
\hline \multirow[t]{2}{*}{ HL } & 12 & 50 & 5 & 9 & 28 & 19 & 2 & 3 \\
\hline & (15.79) & (65.79) & $(6.58)$ & (11.84) & (53.85) & $(36.54)$ & (3.85) & $(5.77)$ \\
\hline \multirow[t]{2}{*}{ LH } & 13 & 4 & 33 & 7 & 30 & 0 & 29 & 0 \\
\hline & $(22.81)$ & $(7.02)$ & $(57.89)$ & (12.28) & $(50.85)$ & $(0.00)$ & $(49.15)$ & $(0.00)$ \\
\hline \multirow[t]{2}{*}{$\mathrm{LL}$} & 38 & 3 & 2 & 24 & 30 & 9 & 1 & 22 \\
\hline & $(56.72)$ & $(4.48)$ & (2.99) & $(35.82)$ & (48.39) & $(14.52)$ & (1.61) & (35.48) \\
\hline
\end{tabular}

Number of agents receiving each message type, percentages in parentheses.

The abbreviations in message part represents message pairs.

$\mathrm{H}=$ High ability $\mathrm{L}=$ Low ability $\mathrm{No}=$ No message.

Table 12: Principal's Strategy in Private Feedback

\begin{tabular}{lcc}
\hline \hline & $(1)$ & $(2)$ \\
& Private Feedback (Minimum) & Private Feedback (Maximum) \\
\hline Agent is high, the other agent is low & -0.027 & $0.255^{* * *}$ \\
& $(0.05)$ & $(0.09)$ \\
Agent is low, the other agent is high & $-0.494^{* * *}$ & $-0.233^{* * *}$ \\
& $(0.04)$ & $(0.04)$ \\
Agent is low, the other agent is low & $-0.235^{* * *}$ & $-0.211^{* * *}$ \\
& $(0.05)$ & $(0.04)$ \\
Risk Aversion & 0.006 & 0.009 \\
& $(0.01)$ & $(0.02)$ \\
Session Controls & Yes & Yes \\
\hline $\mathrm{N}$ & 522 & 468 \\
\hline \hline
\end{tabular}

Logit Regressions, marginal effects. Standard error in parantheses. Errors are clustered across observations.

Dependent variable is private feedback to the agent. It takes value of 1 if principal provides public feedback, 0 otherwise.

${ }^{*} \mathrm{p}<0.10,{ }^{* *} \mathrm{p}<0.05,{ }^{* * *} \mathrm{p}<0.01$.

other agent is of low ability (compared to the case when both are high ability). Also the principal is less likely to send information when the agent has low ability. These are consistent with theory.

In the minimum-private treatment, theory predicts that the principal provides information if both agents have high abilities, which is the behavior exhibited by the majority of principals ( $79 \%$ in $\mathrm{HH}$ ). If the equilibrium is fully informative, then the principal provides information when both agents have low abilities as well, which is the behavior exhibited by the majority (57\%). However, a significant portion of the principals prefer not to provide information to either agent when the state is LL (36\%). Column (1) of Table 12 shows that principals are most likely to give information in state HH, which is consistent with theoretical predictions. They are less likely to give information to the low ability agent, even when both have low ability, suggesting that not all principals play according to the fully informative equilibrium. However, they are less likely to give information to the low ability agent when the other agent has high ability as compared to the case when the other is of low ability ( $p=$ 0.000), which suggests that some principals play according to the fully informative equilibrium. 
Overall, we may summarize our findings as follows.

Result 5 (Feedback Behavior).

1. In teams with best-shot technology, principals' feedback behavior is consistent with theoretical predictions. Predictions E.1 and F.1 are confirmed.

2. In teams with weakest-link technology, principals tend to provide more information than predicted in public-feedback and less information than the fully informative equilibrium in privatefeedback. There is only partial support for Predictions B.1 and C.1.

\section{Concluding Remarks}

Whether and how to give feedback to motivate individuals working in a team is a central question both in educational environments and the workplace. In this paper we theoretically and experimentally investigate the informativeness and the effect of private and public feedback on team performance in environments that are characterized by different performance technologies. We find that the type of team performance technology crucially matters for whether feedback boosts team performance and what type of feedback, if any, is more likely to be effective. In teams whose performance is determined by the best performer, both public and private feedback regimes are better for team performance than a no-feedback regime, while in teams characterized by a weakest-link type technology, giving no feedback is the best option. There is a very close match between predicted and actual performances in every treatment except the weakest-link public feedback case, where actual performance is lower than the predicted one. We show that this is due to the fact that there is more information transmission in that treatment than the theory predicts.

We also find that there is significant information transmission in all treatments, which is good for team performance in the best-shot and bad in the weakest-link technology. This provides an explanation of why feedback is better in best-shot teams and worse in weakest-link teams. Interestingly, there is significantly more information transmission under public feedback when the technology is best-shot as opposed to weakest-link, which is exactly what the theory predicts. This shows that the subjects understand the crucial difference between team technologies in terms of the communication incentives of the principals.

Individuals in our sample behave exactly like rational risk-neutral agents in their effort choice, which validates our theoretical model. In the best-shot treatments, principals behave consistently with the theory and agents interpret feedback as they should, especially under public feedback where there is a unique fully informative equilibrium outcome. In the weakest-link public feedback treatment, there is a unique equilibrium outcome in which the principal sends information only when both agents have high ability. However, principals send more information in the experiment and this leads to a worse team performance than what the theory predicts. In the weakest-link private feedback treatment, there is additionally a fully informative equilibrium and some principals behave consistently with that equilibrium. Also, agents interpret no information more pessimistically under private feedback in comparison with public feedback. These two factors cause team performance to be worse in weakest-link settings under private feedback than under public feedback.

The results suggest that if the motivation and performance of lower-ability agents are important, as in weakest-link type settings with heterogeneous ability, ex-ante it is better to institute a policy of 
no feedback. This is especially relevant in environments such as early education, where low beliefs and motivation may have long-run costs. In contrast, when only the best performers matter, as for example in $R \& D$ settings where one breakthrough idea is sufficient, providing public feedback to boost the high ability individuals' motivation is the best policy.

Obviously, there are some limitations of our work. First, we analyze a setting where the only options available to the principal are telling the truth and withholding information. It would be interesting to extend our work to multiple period interactions and situations in which the principal can lie. Second, conducting similar experiments in the field, both in educational and work environments, would be very interesting.

\section{References}

Ghazala Azmat and Nagore Iriberri. The importance of relative performance feedback information: Evidence from a natural experiment using high school students. Journal of Public Economics, 94 (7):435-452, 2010.

Ghazala Azmat and Nagore Iriberri. The provision of relative performance feedback: An analysis of performance and satisfaction. Journal of Economics \& Management Strategy, 25(1):77-110, 2016.

Ghazala Azmat, Manuel Bagues, Antonio Cabrales, and Nagore Iriberri. What you don't know... can't hurt you? A field experiment on relative performance feedback in higher education. Working Paper, 2016.

Oriana Bandiera, Valentino Larcinese, and Imran Rasul. Blissful ignorance? a natural experiment on the effect of feedback on students' performance. Labour Economics, 34:13-25, 2015.

Iwan Barankay. Rank incentives: Evidence from a randomized workplace experiment. Working Paper, 2012.

Volker Benndorf, Dorothea Kübler, and Hans-Theo Normann. Privacy concerns, voluntary disclosure of information, and unraveling: An experiment. European Economic Review, 75:43-59, 2015.

Johannes Berger, Christine Harbring, and Dirk Sliwka. Performance appraisals and the impact of forced distribution - an experimental investigation. Management Science, 59(1):54-68, 2013.

Jordi Blanes i Vidal and Mareike Nossol. Tournaments without prizes: Evidence from personnel records. Management Science, 57(10):1721-1736, 2011.

Christiane Bradler, Robert Dur, Susanne Neckermann, and Arjan Non. Employee recognition and performance: A field experiment. Management Science, 62(11):3085-3099, 2016.

Gary Charness, David Masclet, and Marie Claire Villeval. Competitive preferences and status as an incentive: Experimental evidence. Working Paper, 2010.

Gary Charness, David Masclet, and Marie Claire Villeval. The dark side of competition for status. Management Science, 60(1):38-55, 2014. 
Samuel A. Culbert. Get rid of the performance review! The Wall Street Journal, October 20 2008. URL http://www.wsj.com/articles/SB122426318874844933. [Online; accessed 16September- 2015].

Florian Ederer and Ernst Fehr. Deception and incentives: How dishonesty undermines effort provision. Working Paper, May 2009.

Tor Eriksson, Anders Poulsen, and Marie Claire Villeval. Feedback and incentives: Experimental evidence. Labour Economics, 16(6):679-688, 2009.

Seda Ertac, Levent Koçkesen, and Duygu Ozdemir. The role of verifiability and privacy in the strategic provision of performance feedback: Theory and experimental evidence. Games and Economic Behavior, 100:24 - 45, 2016.

Urs Fischbacher. z-tree: Zurich toolbox for ready-made economic experiments. Experimental economics, 10(2):171-178, 2007.

Robert Forsythe, R. Mark Isaac, and Thomas R. Palfrey. Theories and tests of "blind bidding" in sealedbid auctions. RAND Journal of Economics, 20:214-238, 1989.

Leonie Gerhards and Neele Siemer. Private versus public feedback-the incentive effects of symbolic awards. Working Paper, 2014.

David Gill, Zdenka Kissová, Jaesun Lee, and Victoria L Prowse. First-place loving and last-place loathing: How rank in the distribution of performance affects effort provision. Management Science, forthcoming, 2017.

Francesco Giovannoni and Daniel J. Seidmann. Secrecy, two-sided bias and the value of evidence. Games and Economic Behavior, 59:296-315, 2007.

Sofoklis Goulas and Rigissa Megalokonomou. Knowing who you are: The effect of feedback information on short and long term outcomes. Working Paper, 2015.

Rebecca Greenfield. So what kind of performance review do you want, anyway?, 2016. URL https://www.bloomberg.com/news/articles/2016-12-15/ so-what-kind-of-performance-review-do-you-want-anyway. Accessed on 24 July 2017.

Sanford J Grossman. The informational role of warranties and private disclosure about product quality. Journal of law and economics, 24(3):461-483, 1981.

Oliver Gürtler and Christine Harbring. Feedback in tournaments under commitment problems: Experimental evidence. Journal of Economics \& Management Strategy, 19(3):771-810, 2010.

Jeanne Hagenbach and Eduardo Perez-Richet. Communication with evidence in the lab. Working Paper, 2017.

Jeanne Hagenbach, Frédéric Koessler, and Eduardo Perez-Richet. Certifiable pre-play communication: Full disclosure. Econometrica, 82:1093-1131, 2014. 
Glenn W Harrison and Jack Hirshleifer. An experimental evaluation of weakest link/best shot models of public goods. Journal of Political Economy, 97(1):201-225, 1989.

Jack Hirshleifer. From weakest-link to best-shot: The voluntary provision of public goods. Public Choice, 41(3):371-386, 1983.

Charles A Holt and Susan K Laury. Risk aversion and incentive effects. The American Economic Review, 92(5):1644-1655, 2002.

Eric Jackson. Ten biggest mistakes bosses make in performance reviews. Forbes, 2012. URL http://www.forbes.com/sites/ericjackson/2012/01/09/ ten-reasons-performance-reviews-are-done-terribly. [Accessed 24-August-2015].

Ginger Zhe Jin, Michael Luca, and Daniel Martin. Is no news (perceived as) bad news? An experimental investigation of information disclosure. Working Paper, 2015.

Edi Karni. A mechanism for eliciting probabilities. Econometrica, 77(2):603-606, 2009.

Ronald R King and David E Wallin. Voluntary disclosures when seller's level of information is unknown. Journal of Accounting Research, pages 96-108, 1991.

Rebecca Knight. How to give your team feedback. Harvard Business Review, 2016.

Frédéric Koessler. Lobbying with two audiences: Public vs private certification. Mathematical Social Sciences, 55(3):305-314, 2008.

Camelia M Kuhnen and Agnieszka Tymula. Feedback, self-esteem, and performance in organizations. Management Science, 58(1):94-113, 2012.

Clinton O Longenecker, Henry P Sims Jr, and Dennis A Gioia. Behind the mask: The politics of employee appraisal. The Academy of Management Executive, pages 183-193, 1987.

Jérôme Mathis. Full revelation of information in sender-receiver games of persuasion. Journal of Economic Theory, 143:571-584, 2008.

Paul R Milgrom. Good news and bad news: Representation theorems and applications. The Bell Journal of Economics, pages 380-391, 1981.

Markus M Mobius, Muriel Niederle, Paul Niehaus, and Tanya S Rosenblat. Managing self-confidence: Theory and experimental evidence. Working Paper, 2014.

Alwine Mohnen and Kathrin Manthei. Is honesty the best policy? An experimental study on the honesty of feedback in employer-employee relationships. Working Paper, 2006.

Canice Prendergast. The provision of incentives in firms. Journal of Economic Literature, 37(1):7-63, March 1999.

Julie Rosaz. Biased information and effort. Economic Inquiry, 50(2):484-501, 2012.

Julie Rosaz, Robert Slonim, and Marie Claire Villeval. Quitting and peer effects at work. Labour Economics, 39:55 - 67, 2016. 
Daniel J Seidmann and Eyal Winter. Strategic information transmission with verifiable messages. Econometrica, 65(1):163-169, 1997.

Daniel Taylor. Louis van gaal tactics left manchester united players close to mutiny. The Guardian, 2016. URL https://www.theguardian.com/football/blog/2016/may/22/ louis-van-gaal-manchester-united-players-near-mutiny. Accessed July 272017.

Anh Tran and Richard Zeckhauser. Rank as an inherent incentive: Evidence from a field experiment. Journal of Public Economics, 96(9):645 - 650, 2012.

Neil D Weinstein. Unrealistic optimism about future life events. Journal of personality and social psychology, 39(5):806, 1980. 


\section{A Proofs (For online publication only)}

Proof of Lemma 1. Suppose, for contradiction, that $\rho(l, h)=(l, h)$. Equilibrium payoff of the principal is then equal to

$$
\begin{aligned}
\min \left\{q_{1}\left(e_{1}^{*}\left(\mu_{1}(\rho(l, h))\right), l\right), q_{2}\left(e_{2}^{*}\left(\mu_{2}(\rho(l, h))\right), h\right)\right\} & =\min \left\{q_{1}\left(e_{1}^{*}(l, h), l\right), q_{2}\left(e_{2}^{*}(l, h), h\right)\right\} \\
& =q_{1}\left(e_{1}^{*}(l, h), l\right)
\end{aligned}
$$

which follows from

$$
q_{1}\left(e_{1}^{*}(l, h), l\right)<q_{1}\left(e_{1}^{*}(l, h), h\right)=q_{2}\left(e_{1}^{*}(l, h), h\right)<q_{2}\left(e_{2}^{*}(l, h), h\right)
$$

where the first inequality follows from the fact that $q_{1}$ is strictly increasing in $\theta_{1}$, the equality from the symmetry of the output functions, and the last inequality from equilibrium effort function given by (13).

Suppose first that $\rho(\theta)=n$ for some $\theta \in \Theta$. Since $\rho(l, h)=(l, h)$, $\operatorname{supp}\left(\mu_{i}(n)\right) \subseteq\{(h, l),(h, h),(l, l)\}$. This implies that $\mu_{1}(n)>_{1} \mu_{1}(l, h)$ and hence

$$
q_{1}\left(e_{1}^{*}\left(\mu_{1}(n)\right), l\right)>q_{1}\left(e_{1}^{*}(l, h), l\right) .
$$

by effort monotonicity. We also have

$$
\left.\left.q_{2}\left(e_{2}^{*}\left(\mu_{2}(n)\right), h\right)\right) \geq q_{2}\left(e_{2}^{*}(h, l), h\right)\right)=q_{1}\left(e_{1}^{*}(l, h), h\right)>q_{1}\left(e_{1}^{*}(l, h), l\right)
$$

where the equality follows from the output and effort symmetry conditions. But then

$$
\left.\min \left\{q_{1}\left(e_{1}^{*}\left(\mu_{1}(n)\right), l\right)\right), q_{2}\left(e_{2}^{*}\left(\mu_{2}(n)\right), h\right)\right\}>q_{1}\left(e_{1}^{*}(l, h), l\right)
$$

which contradicts the sequential rationality condition (5).

Suppose now that $\rho(\theta)=\theta$ for all $\theta \in \Theta$. If $\operatorname{supp}\left(\mu_{1}(n)\right) \neq\{(l, h)\}$, then $\mu_{1}(n)>_{1} \mu_{1}(l, h)$ and we contradict sequential rationality in the same way as above. Therefore, $\operatorname{supp}\left(\mu_{1}(n)\right)=\{(l, h)\}$ and consistency of off-the-equilibrium beliefs implies that $\operatorname{supp}\left(\mu_{2}(n)\right)=\{(l, h)\}$. But then

$$
\begin{aligned}
\min \left\{q_{1}\left(e_{1}^{*}\left(\mu_{1}(\rho(h, l))\right), h\right), q_{2}\left(e_{2}^{*}\left(\mu_{2}(\rho(h, l))\right), l\right)\right\} & \left.=q_{2}\left(e_{2}^{*}(h, l)\right), l\right) \\
& \left.=q_{1}\left(e_{1}^{*}(l, h)\right), l\right) \\
& <\min \left\{q_{1}\left(e_{1}^{*}(l, h), h\right), q_{2}\left(e_{2}^{*}(l, h), l\right)\right\} \\
& =\min \left\{q_{1}\left(e_{1}^{*}\left(\mu_{1}(n)\right), h\right), q_{2}\left(e_{2}^{*}\left(\mu_{2}(n)\right), l\right)\right\}
\end{aligned}
$$

This implies that type $(h, l)$ has a profitable deviation to $n$, contradicting sequential rationality condition (5). We can prove that $\rho(h, l)=n$ in a similar way. 
Proof of Proposition (2). Let $\operatorname{prob}\left(\theta_{i}=h\right)=\gamma \in(0,1)$. Equilibrium effort function (13) implies that

$$
\begin{array}{r}
e_{i}^{*}(p)=(1-\alpha)\left(p_{i} h+\left(1-p_{i}\right) l\right), e_{i}^{*}(h, h)=(1-\alpha) h, e_{i}^{*}(l, l)=(1-\alpha) l, e_{i}^{*}(h, l)=h-\alpha l \\
e_{i}^{*}(l, h)=l-\alpha h, e_{i}^{*}\left(p_{\{\{(h, h),(h, l)\}}=h-\alpha\left(p_{i} h+\left(1-p_{i}\right) l\right), e_{i}^{*}\left(p_{\mid\{(h, h),(l, h)\}}\right)=p_{i} h+\left(1-p_{i}\right) l-\alpha h\right. \\
e_{i}^{*}\left(p_{\mid\{(h, h),(l, l)\}}\right)=(1-\alpha)\left(p_{i} h+\left(1-p_{i}\right) l\right), e_{i}^{*}\left(p_{\{\{(h, l),(l, h)\}}\right)=(1-\alpha)\left(p_{i} h+\left(1-p_{i}\right) l\right) \\
e_{i}^{*}\left(p_{\mid\{(h, l),(l, l)\}}\right)=p_{i} h+\left(1-p_{i}\right) l-\alpha l, e_{i}^{*}\left(p_{\mid\{(l, h),(l, l)\}}\right)=l-\alpha\left(p_{i} h+\left(1-p_{i}\right) l\right) \\
e_{i}^{*}\left(p_{\mid\{(h, h),(h, l),(l, h)\}}\right)=\frac{1-\alpha}{2-p_{i}}\left(h+\left(1-p_{i}\right) l\right), e_{i}^{*}\left(p_{\mid\{(h, h),(h, l),(l, l)\}}\right)=\frac{p_{i}\left(1-\alpha p_{i}\right)}{p_{i}^{2}-p_{i}+1} h+\frac{\left(1-p_{i}\right)\left(1-\alpha-p_{i}\right)}{p_{i}^{2}-p_{i}+1} l \\
e_{i}^{*}\left(p_{\mid\{(h, h),(l, h),(l, l)\}}\right)=\frac{p_{i}\left(p_{i}-\alpha\right)}{p_{i}^{2}-p_{i}+1} h+\frac{\left(1-p_{i}\right)\left(1-\alpha\left(1-p_{i}\right)\right)}{p_{i}^{2}-p_{i}+1} l, e_{i}^{*}\left(p_{\mid\{(l, h),(h, l),(l, l)\}}\right)=(1-\alpha) \frac{l+p_{i} h}{1+p_{i}}
\end{array}
$$

$e_{i}^{*}(h, h)>e_{i}^{*}(p)$ and $e_{i}^{*}(h, h)>e_{i}^{*}\left(p_{\{\{(l, h),(h, l)\}}\right)$ imply that $\rho(h, h)=(h, h)$, while $e_{i}^{*}\left(p_{\{\{(l, h),(h, l)\}}\right)>e_{i}^{*}(l, l)$ implies that $\rho(l, l)=n$. Lemma (1) completes the necessity part of the proof. Sufficiency is easy to prove since $e_{i}^{*}(h, h)>e_{i}^{*}\left(p_{\{\{(l, h),(h, l),(l, l)\}}\right)>e_{i}^{*}(l, l)>e_{i}^{*}(l, h)$.

Proof of Lemma 2. Let $\rho_{i}(\theta) \neq \rho_{i}\left(\theta^{\prime}\right)$ for any $\theta \neq \theta^{\prime}$ and $i=1,2$ in equilibrium and suppose, for contradiction, that $\mu_{1}(n) \neq(l, h)$. This implies that $\mu_{1}(n)>_{1} \mu_{1}(l, h)$. Since $\mu_{2}(n) \geq_{2} \mu_{2}(h, l)$, this implies

$$
\begin{aligned}
\left.\min \left\{q_{1}\left(e_{1}^{*}\left(\mu_{1}(n)\right), l\right)\right), q_{2}\left(e_{2}^{*}\left(\mu_{2}(n)\right), h\right)\right\} & >q_{1}\left(e_{1}^{*}(l, h), l\right) \\
& \left.=\min \left\{q_{1}\left(e_{1}^{*}\left(\mu_{1}\left(\rho_{1}(l, h)\right)\right), l\right)\right), q_{2}\left(e_{2}^{*}\left(\mu_{2}\left(\rho_{2}(l, h)\right)\right), h\right)\right\} .
\end{aligned}
$$

This shows that $r_{1}=r_{2}=n$ is a profitable deviation for $(l, h)$ and contradicts sequential rationality condition (9). Similarly, we can show that $\mu_{2}(n)=(h, l)$.

Proof of Proposition 3. Consider the assessment defined in (14). Beliefs satisfy the consistency conditions (10) and (11). Now take any $\theta \in\{(l, l),(h, h)\}$ and consider any deviation to $\left(r_{1}, r_{2}\right)$ where $r_{i} \in\{\theta, n\}$ and $r_{i}=n$ for some $i=1,2$. Let $r_{1}=n$ without loss of generality. Such a deviation yields

$$
\begin{aligned}
\left.\min \left\{q_{1}\left(e_{1}^{*}\left(\mu_{1}(n)\right), \theta_{1}\right)\right), q_{2}\left(e_{2}^{*}\left(\mu_{2}\left(r_{2}\right)\right), \theta_{2}\right)\right\} & =q_{1}\left(e_{1}^{*}(l, h), \theta_{1}\right) \\
& \left.\leq \min \left\{q_{1}\left(e_{1}^{*}\left(\mu_{1}\left(\rho_{1}(\theta)\right)\right), \theta_{1}\right)\right), q_{2}\left(e_{2}^{*}\left(\mu_{2}\left(\rho_{2}(\theta)\right)\right), \theta_{2}\right)\right\} .
\end{aligned}
$$

and hence is not profitable.

Let $\theta=(l, h)$ and note that the principal's payoff under the assessment $(14)$ is $q_{1}\left(e_{1}^{*}\left(\mu_{1}(l, h), l\right)\right)$. Consider any deviation to $\left(r_{1}, r_{2}\right)$ where $r_{i} \in\{\theta, n\}$ and $r_{i}=n$ for some $i=1,2$. If $r_{1}=(l, h)$, her payoff does not change. So, let $r_{1}=n$. Her payoff does not change in this case either because $\mu_{1}(n)=(l, h)$. Therefore, type $(l, h)$ does not have a profitable deviation. We can similarly show that type $(h, l)$ does not have a profitable deviation either, which completes the proof of sequential rationality.

Proof of Proposition (4). Suppose $\rho_{i}(h, h)=n$. This implies that $e_{i}^{*}\left(\mu_{i}(n)\right) \geq e_{i}^{*}((h, h))>e_{i}^{*}((l, l))>$ $e_{i}^{*}((l, h))$, which, in turn, implies that $\rho_{i}(l, l)=\rho_{i}(l, h)=n$. But this contradicts $e_{i}^{*}\left(\mu_{i}(n)\right) \geq e_{i}^{*}((h, h))$. Therefore, $\rho_{i}(h, h)=(h, h)$. If only $\rho_{i}(l, h)=n$, then we have the fully informative equilibrium. If only $\rho_{i}(l, l)=\rho_{i}(l, h)=n$, then $(l, l)$ would deviate and provide feedback. Therefore, $\rho_{i}(l, l)=\rho_{i}(l, h)=$ $\rho_{i}(h, l)=n$. This is indeed an equilibrium since, $e_{i}^{*}(h, h)>e_{i}^{*}\left(p_{\{\{(l, h),(h, l),(l, l)\}}\right)>e_{i}^{*}(l, l)>e_{i}^{*}(l, h)$, for $i=$ 1,2 . 
Proof of Proposition 5. We first show that types $(h, l)$ and $(l, h)$ do not pool with any other type.

Lemma 3. In any equilibrium, $\rho(h, l) \neq \rho(\theta)$ for any $\theta \neq(h, l)$ and $\rho(l, h) \neq \rho(\theta)$ for any $\theta \neq(l, h)$.

Proof of Lemma 3. Suppose, for contradiction, that $\rho(h, l)=\rho(\theta)$ for some $\theta \neq(h, l)$. This implies that $\mu_{1}(h, l)>_{1} \mu_{1}(\rho(h, l))$ and hence

$$
\begin{aligned}
\max \left\{q_{1}\left(e_{1}^{*}\left(\mu_{1}(\rho(h, l))\right), h\right), q_{2}\left(e_{2}^{*}\left(\mu_{2}(\rho(h, l))\right), l\right)\right\} & <q_{1}\left(e_{1}^{*}\left(\mu_{1}(h, l)\right), h\right) \\
& =\max \left\{q_{1}\left(e_{1}^{*}\left(\mu_{1}(h, l)\right), h\right), q_{2}\left(e_{2}^{*}\left(\mu_{2}(h, l)\right), l\right)\right\}
\end{aligned}
$$

But then type $(h, l)$ has a profitable deviation to $(h, l)$, which contradicts sequential rationality condition (5). Proof of the claim that $(l, h)$ does not pool with any other type is similar.

We next prove that type $(h, h)$ does not pool with any other type.

Lemma 4. In any equilibrium $\rho(h, h) \neq \rho(\theta)$ for any $\theta \neq(h, h)$.

Proof of Lemma 4. Suppose, for contradiction, that $\rho(h, h)=\rho(\theta)$ for some $\theta \neq(h, h)$. Lemma 3 implies that $\theta=(l, l)$ and $\mu_{i}(h, h)>_{i} \mu_{i}(\rho(h, h))$ for $i=1,2$. Therefore,

$\max \left\{q_{1}\left(e_{1}^{*}\left(\mu_{1}(\rho(h, h))\right), h\right), q_{2}\left(e_{2}^{*}\left(\mu_{2}(\rho(h, h))\right), h\right)\right\}<\max \left\{q_{1}\left(e_{1}^{*}\left(\mu_{1}(h, h)\right), h\right), q_{2}\left(e_{2}^{*}\left(\mu_{2}(h, h)\right), h\right)\right\}$.

This implies that type $(h, h)$ has a profitable deviation to $(h, h)$, which contradicts sequential rationality condition (5).

Lemma 3 and 4 imply that all pure strategy equilibria must be fully revealing. For sufficiency, consider the following assessment:

$$
\rho(\theta)=\theta, \mu_{i}(\theta)=\theta, \forall \theta \in \Theta, \mu_{i}(n)=(l, l), i=1,2 .
$$

It is easy to verify that this assessment constitutes an equilibrium.

Proof of Proposition 6. We first show that types $(h, l)$ and $(l, h)$ do not pool with any other type.

Lemma 5. In any equilibrium, $\rho_{1}(h, l) \neq \rho_{1}(\theta)$ for any $\theta \neq(h, l)$ and $\rho_{2}(l, h) \neq \rho_{2}(\theta)$ for any $\theta \neq(l, h)$.

Proof of Lemma 5. Suppose, for contradiction, that $\rho_{1}(h, l)=\rho_{1}(\theta)$ for some $\theta \neq(h, l)$. This implies that $\mu_{1}(h, l)>_{1} \mu_{1}\left(\rho_{1}(h, l)\right)$ and hence

$$
\begin{aligned}
\max \left\{q_{1}\left(e_{1}^{*}\left(\mu_{1}\left(\rho_{1}(h, l)\right)\right), h\right), q_{2}\left(e_{2}^{*}\left(\mu_{2}\left(\rho_{2}(h, l)\right)\right), l\right)\right\} & <q_{1}\left(e_{1}^{*}\left(\mu_{1}(h, l)\right), h\right) \\
& =\max \left\{q_{1}\left(e_{1}^{*}\left(\mu_{1}(h, l)\right), h\right), q_{2}\left(e_{2}^{*}\left(\mu_{2}\left(\rho_{2}(h, l)\right)\right), l\right)\right\}
\end{aligned}
$$

Therefore, for type $(h, l)$ it is strictly better to report $(h, l)$ to agent 1 , which contradicts sequential rationality condition (9). Proof of the claim that $\rho_{2}(l, h) \neq \rho_{2}(\theta)$ for any $\theta \neq(l, h)$ is similar.

We next prove that type $(h, h)$ reports truthfully to at least one of the agents.

Lemma 6. In any equilibrium, there exists $i \in\{1,2\}$ such that $\theta \neq(h, h)$ implies $\rho_{i}(h, h) \neq \rho_{i}(\theta)$. 
Proof of Lemma 6. Suppose, for contradiction, that $\rho_{1}(h, h)=\rho_{1}\left(\theta^{\prime}\right)$ for some $\theta^{\prime} \neq(h, h)$ and $\rho_{2}(h, h)=$ $\rho_{2}\left(\theta^{\prime \prime}\right)$ for some $\theta^{\prime \prime} \neq(h, h)$. Lemma 5 implies that $\theta^{\prime} \neq(h, l)$ and $\theta^{\prime \prime} \neq(l, h)$. This implies that $\mu_{i}(h, h)>_{i}$ $\mu_{i}\left(\rho_{i}(h, h)\right)$ for $i=1,2$ and hence

$$
\max \left\{q_{1}\left(e_{1}^{*}\left(\mu_{1}(\rho(h, h))\right), h\right), q_{2}\left(e_{2}^{*}\left(\mu_{2}(\rho(h, h))\right), h\right)\right\}<\max \left\{q_{1}\left(e_{1}^{*}\left(\mu_{1}(h, h)\right), h\right), q_{2}\left(e_{2}^{*}\left(\mu_{2}(h, h)\right), h\right)\right\}
$$

But then type $(h, h)$ has a profitable deviation to reporting $(h, h)$ to both agents, which contradicts sequential rationality condition (9).

This concludes the proof.

\section{B Instructions, Quiz, and Survey (For online publication only)}

\section{B.1 Instructions ${ }^{33}$}

Welcome. Thank you for participating in our study, which is about economic decision making. You will earn 10 TL for your participation. Besides this show-up fee, your earnings in the experiment will depend on your decisions and chance. There is no misleading or deception in this study. The rules that we will state are completely correct and your payment will be determined accordingly. Payments will be made privately and in cash at the end of the experiment. Your decisions during the experiment will be recorded under a subject number and will never be matched with your identifying information.

The experiment consists of 3 parts and within each part there will be 2, 9 and 9 periods respectively. At the end, three periods out of the total of 20 periods will be randomly selected and your earnings will be determined according to your total payoff in these chosen periods. In addition, there will be a separate task at the end where you can earn money, and the study will conclude with a brief survey. During the experiment, all monetary earnings will be denoted in ECU ("experimental currency units"), where 1 ECU equals $0.03 \mathrm{TL}$.

\section{General Rules}

At the beginning of the experiment, participants will be randomly assigned to one of the roles of "Principal" and "Agent". In each period, 3-person groups that consist of one principal and two agents will be formed. At the beginning of each period, groups will be reshuffled and formed again.

The computer will assign an "ability factor" to each agent randomly. Each agent will have "high" ability with $50 \%$ chance, and "low" ability with $50 \%$ chance. As an agent, you will not know if you have high or low ability. The abilities of the agents will be randomly determined at the beginning of each period, and will not be fixed throughout the experiment.

\section{Agents' Decision:}

In each period, agents will make an "effort" decision. How much return putting effort will bring will be determined by:

\section{The agent's own ability}

\footnotetext{
${ }^{33}$ Original instructions were in Turkish and are available upon request. Note that verbal instructions were supplemented with graphical slides to ease understanding. These are also available upon request. The instructions given here are for the maximum technology and the following treatment order configuration: No Information, Private Feedback, and Public Feedback.
} 


\begin{tabular}{lll}
\hline & \multicolumn{2}{l}{ Other's ability } \\
\cline { 2 - 3 } Own ability & High & Low \\
\hline High & 10 & 14 \\
Low & 2 & 6 \\
\hline
\end{tabular}

2. The ability of the other agent in his group

The return to an agent's effort will be

- higher if the agent has "high" ability

- higher if the other agent has "low" ability

The effort decision will be made by selecting an effort level between 1 and 16. As an agent, the productivity of one unit of effort will depend on your own ability and the other agent's ability. Productivity of a unit of effort is like this [show on slide]:

There is also a cost to putting effort. As effort increases, the cost of effort increases as well.

Agent's payoff is determined by the formula:

$$
\text { Agent's payoff }=\text { Productivity } * \text { Effort }-\frac{\text { Effor } t^{2}}{2}
$$

Agents' payoffs from each effort level for each ability combinations given in this table, and will be provided to you when you make your decisions [show on slide].

Table 13: Agents' Payoffs

\begin{tabular}{crrrr}
\hline & \multicolumn{4}{c}{ Ability (own, other $)$} \\
\cline { 2 - 5 } My Effort & (High, Low) & (High, High) & (Low, Low) & (Low, High) \\
\hline 1 & 13.5 & 9.5 & 5.5 & 1.5 \\
2 & 26 & 18 & 10 & $\mathbf{2}$ \\
3 & 37.5 & 25.5 & 13.5 & 1.5 \\
4 & 48 & 32 & 16 & 0 \\
5 & 57.5 & 37.5 & 17.5 & -2.5 \\
6 & 66 & 42 & $\mathbf{1 8}$ & -6 \\
7 & 73.5 & 45.5 & 17.5 & -10.5 \\
8 & 80 & 48 & 16 & -16 \\
9 & 85.5 & 49.5 & 13.5 & -22.5 \\
10 & 90 & $\mathbf{5 0}$ & 10 & -30 \\
11 & 93.5 & 49.5 & 5.5 & -38.5 \\
12 & 96 & 48 & 0 & -48 \\
13 & 97.5 & 45.5 & -6.5 & -58.5 \\
14 & $\mathbf{9 8}$ & 42 & -14 & -70 \\
15 & 97.5 & 37.5 & -22.5 & -82.5 \\
16 & 96 & 32 & -32 & -96 \\
\hline
\end{tabular}

Each period, agents will have an endowment of 100 ECU and principals will have 120 ECU. Any losses will be deducted from this endowment and any gains will be added. 


\section{Agent's Guesses About Abilities}

As you know, there are 4 possible scenarios about the abilities in a group:

- Both of us agents have high ability

- I have high ability, the other agent has low ability

- I have low ability, the other agent has high ability

- Both of us agents have low ability

All agents will be asked to make guesses about the likelihood of these 4 scenarios. For example: HighHigh $=30 \%$, High-Low $=40 \%$, Low-High $=20 \%$, Low-Low $=30 \%$ etc. We are going to use a mechanism so that everyone states their true beliefs here. First, let's demonstrate how this mechanism works with a simple example.

Let's say you believe that the chances of the weather being sunny tomorrow is $70 \%$. You have a chance to earn 10 ECU. There are two options. Your can either choose to base your payoff on the weather being sunny, or leave it to a chance mechanism. If you base your payoff on the weather, you gain $10 \mathrm{ECU}$ if the weather is sunny, and $0 \mathrm{ECU}$ if it is not. The chance mechanism, on the other hand, gives you 10 ECU with X\% chance, and 0 ECU with $100-X \%$ chance. So, if you base your payoff on the chance mechanism, your chance to win $10 \mathrm{ECU}$ is X\%. Now, the computer will choose the probability of winning in the chance mechanism $(\mathrm{X})$ randomly. You make the decision of whether or not you want to base your payoff on the weather or chance by answering the following question:

What is the minimum \% chance of winning in the chance mechanism $(X)$, that will make you willing to leave your payoff to the chance mechanism rather than the weather being sunny?

For example, suppose I believe that the chances of the weather being sunny tomorrow is $70 \%$.

What should I do if the probability of winning is $40 \%$ in the chance mechanism? I should base my payoff on the weather, instead of the chance mechanism.

What should I do if the probability of winning is $80 \%$ in the chance mechanism? I should choose to base my payoff on the chance mechanism.

So, if you believe that the chances of a sunny weather is $70 \%$ :

- If the chance mechanism gives a winning chance of at least $70 \%$, you should select the chance mechanism.

- If the chance mechanism has a winning chance of less than $70 \%$, you should base your payment on the weather, instead of chance mechanism.

So in this case, what is best for you is to state your true beliefs about the chances of a sunny weather.

We are going to use a similar mechanism in the guessing stage of the experiment.

You will make guesses about four possible scenarios $(H H, H L, L H, L L)$. As an agent, you have the opportunity to win extra 10 ECU from one of your guesses. One of your guesses will be randomly selected by the computer.

For each ability combination, agents can base their payoff on that ability combination being right (as it is in the weather example), or leave it to the chance mechanism. To do this, every agent will state the minimum chance of winning in the chance mechanism that would make them leave their payoff to the chance mechanism. 
For example, let's consider the case "Both of us have high ability". Suppose an agent states that the minimum chance of winning in the chance mechanism that would make him/her leave her payoff to the chance mechanism is $\mathbf{3 0 \%}$. Recall that the computer chooses the probability of winning, $X$, in the chance mechanism randomly. For example, if the chances of winning in the chance mechanism turns out to be 55\%, the agent leaves his/her payoff to chance. In this case, the agent would win $10 \mathrm{ECU}$ with $55 \%$ chance, and $0 \mathrm{ECU}$ with $45 \%$ chance. If the chances of winning in the chance mechanism turns out to be $15 \%$, the agent would base her payoff on both abilities being high. The agent would win $10 \mathrm{ECU}$ if both of the agents actually have high ability, 0 ECU if not.

In this stage, what is best for you is to state what you really think about the likelihood of the four ability combinations. As an extreme example, if you think that the likelihood of a combination is zero, it makes monetary sense to leave your payoff to the chance. Or if you think the likelihood of a combination is $\mathbf{1 0 0 \%}$, it makes monetary sense to base your payoff to that combination.

Now you will see a quiz in your computer screen. The experiment will not progress until everyone answers the questions correctly. Please raise your hand if you have any questions.

[Quiz: see Section B.2]

\section{Principals' Decision}

In the experiment, some subjects will have the role of principal, and some of them will be in the role of agent. In each period, 3-person groups that consist of one principal and two agents will be randomly formed. At the beginning of each period, groups will be reshuffled and formed again. Your roles might change from period to period. Principals' payoff will depend on the efforts and abilities of the agents in his/her group.

An agent's return for a principal is:

- Higher if the agent has more ability

- Higher if the agent exerts more effort

- Specifically, $10 * E$ ffor $t$ if the agent has high ability, $5 * E$ ff or $t$ if the agent has low ability

Payoff function of the principal is as follows:

$$
\text { Principal's payoff }=\max \left\{G_{1}, G_{2}\right\}
$$

So, principals' payoff depends on the maximum return that she/he obtains from the agents.

For example, let's suppose one agent has high, and the other has low ability. The high-ability agent's effort is 12 , and the other agent's effort is 5 . The principal's payoff is $\max \{120,25\}=120$. Thus, if the principal obtains high return from one agent, the other agent's effort does not matter as it will not affect his/her payoff.

At the start of each period, principals will learn the abilities of the agents in their group (recall that agents do not know their own abilities). Then, they will be asked to guess what each agent thinks about both his/her own ability and the other agent's ability. The relevant question will be:

"How much probability do you think Agent 1 places on these four states $(H H, H L, L H, L L)$ ?

One of the guesses that the principal makes will be randomly selected by the computer. If the principal's guess is within \pm 5 percentage points of the agent's stated belief, the principal will earn 10 ECU extra. For example, let's say Agent 1 thinks that the probability that he has high ability and 
the other agent has low ability is $25 \%$. The principal will earn an extra $10 \mathrm{ECU}$, if his/her guess is in the range $[20 \%, 30 \%]$. At the end of the experiment, these extra earnings in the chosen round will be added to the payoff from that round. Do you have any questions?

We will now explain Part 1 of the experiment.

\section{Part 1 (No Information):}

This part will last 2 periods.

As explained before, 3-person groups, consisting of 1 principal and 2 agents, will be formed in each period, randomly.

Agents' payoffs will be based on their efforts and abilities. In addition, they will make guesses about the chances of each ability combination (HH,HL,LH,LL) being true, as explained before.

Agents will not observe their own and the other agent's ability, when they are making their effort choice. The only thing they know will be the probabilities of each agent having high or low ability. Each agent will have high or low ability with $50 \%$ chance, and these probabilities are independent. So each scenario among $(H H, H L, L H, L L)$ may occur with $25 \%$ chance.

Now please look at the table provided to you. What happens if an agent puts an effort of 10 ? or an effort of 5 ? [Show the effort table]

Principals will know each agent's ability. How much a principal earns will depend on the agents' abilities and effort levels, which determine agents' performances. The effort of a high ability agent earns more for the principal (10) than a low ability agent's effort (5). The principal's payoff function will be the maximum of the agents' performances. For example, if both agents are high ability and both choose an effort of 8 , principal's payoff will be equal to $\max \{80,40\}=80$. If the high ability agent chooses an effort of 5 , and the low one chooses 8 , the principal's payoff will be equal to $\max \{50,40\}=$ 50. [Show the table below] Any questions?

\begin{tabular}{|c|c|c|}
\hline High & Low & Payoff \\
\hline 8 & 8 & 80 \\
\hline 8 & 5 & 80 \\
\hline 5 & 8 & 50 \\
\hline 5 & 5 & 50 \\
\hline
\end{tabular}

The principal will also be asked to guess, for each agent, what that agent believes about the likelihood of each ability combination HH, HL, LH and LL. Recall that agents don't know their abilities. If the principal's guess is within \pm 5 percentage points of the agent's stated probability, he/she will earn 10 ECU extra (for each successful guess). At the end of the experiment, these extra earnings in the chosen round will be added to the payoff from that round. Do you have any questions? OK, we will now start the computer program. We will explain the rules in the next parts after this part ends.

\section{Part 2 (Private Feedback):}

This part will last for 9 periods.

Again, 3-person groups, consisting of 1 principal and 2 agents, will be formed in each period, randomly.

Agents' payoffs will be based on their efforts and abilities. In addition, they will make guesses about the chances of each ability combination (HH,HL,LH,LL) being true, as explained before.

Principals will know each agent's ability at the start of the period. How much a principal earns will depend on the agents' abilities and effort levels, which determine agents' performances. The effort of 
a high ability agent earns more for the principal (10) than a low ability agent's effort (5). The principal's payoff function will be the maximum of the agents' performances. For example, if both agents are high ability and both choose an effort of 8 , principal's payoff will be equal to $\max \{80,40\}=80$. If the high ability agent chooses an effort of 5 , and the low one chooses 8 , the principal's payoff will be equal to $\max \{50,40\}=50$. [Show the table below] Any questions?

\begin{tabular}{|c|c|c|}
\hline High & Low & Payoff \\
\hline 8 & 8 & 80 \\
\hline 8 & 5 & 80 \\
\hline 5 & 8 & 50 \\
\hline 5 & 5 & 50 \\
\hline
\end{tabular}

\section{Principal's information decision}

After the principal is shown the abilities of both agents, the principal may choose to reveal or not reveal the true abilities in private messages to each agent. Any message sent by the principal must be true (the principal cannot lie). However, principals may choose not to send any information. If the principal chooses to reveal information, this message has to include information about both agents' abilities. The feedback sent by the principal will be private, which means principals are able to send different messages to different agents.

Specifically, the principal can choose to:

- show the true abilities to only one agent, and not give information to the other

- show the true abilities to each agent (privately)

- not to give any information to any agent

For example, consider a scenario where agent 1's ability is low, and agent 2's ability is high. The principal can send following messages to agent 1 and 2:

- The message to agent 1 can either be "You have low ability, the other agent has high ability" or no information.

- The message to agent 2 can either be "You have high ability, the other agent has low ability" or no information.

As an agent, if you receive an information in this part of the experiment, it has to be true. If you don't receive any information, this is the principal's choice (and the principal knows your and the other agent's ability). If you don't receive any information, it does not mean that the other agent also did not receive any information.

As in the previous treatment, the principals will also be asked to guess, for each agent, the probabilities of each state $(H H, H L, L H, L L)$ as stated by that agent. If the principal's guess is within \pm 5 percentage points of the agent's stated probability, he/she will earn 10 ECU extra (for each successful guess). At the end of the experiment, these extra earnings in the chosen round will be added to the payoff from that round. ${ }^{34}$

\footnotetext{
${ }^{34}$ Screenshots of the principal's and the agents' decision and guess screens were shown on the slides. These are available upon request.
} 
Do you have any questions?

\section{Part 3 (Public Feedback):}

This part will last for 9 periods.

Again, 3-person groups, consisting of 1 principal and 2 agents, will be formed in each period, randomly.

Agent's payoffs will be based on their efforts and abilities. In addition, they will make guesses about the chances of each ability combination (HH,HL,LH,LL) being true, as explained before.

Principals will know each agent's ability at the start of the period. How much a principal earns will depend on the agents' abilities and effort levels, which determine agents' performances. The effort of a high ability agent earns more for the principal (10) than a low ability agent's effort (5). The principal's payoff function will be the maximum of the agents' performances. For example, if both agents are high ability and both choose an effort of 8 , principal's payoff will be equal to $\max \{80,40\}=80$. If the high ability agent chooses an effort of 5 , and the low one chooses 8 , the principal's payoff will be equal to $\max \{50,40\}=50$. [Show the table below] Any questions?

\begin{tabular}{|c|c|c|}
\hline High & Low & Payoff \\
\hline 8 & 8 & 80 \\
\hline 8 & 5 & 80 \\
\hline 5 & 8 & 50 \\
\hline 5 & 5 & 50 \\
\hline
\end{tabular}

\section{Principal's information decision}

After the principal is shown the abilities of both agents, the principal may choose to reveal or not reveal the true abilities in a public message to both agents. Any message sent by the principal has to be true (the principal cannot lie). However, principals may choose not to send any information. If the principal chooses to reveal information, this message has to include information about both agents' abilities. The feedback sent by the principal will be public, which means principals are only able to send a single message to both agents. That is, the principal either sends information about both abilities in a public message to both agents, or does not send any message. Sending a message to only one agent privately is not allowed.

For example, consider a scenario where Agent 1's ability is low, and Agent 2's ability is high. The principal has two options, he/she can either:

- send true information to both agents, indicating that Agent 1 has low and Agent 2 has high ability.

- or not send any information.

As an agent, in this part of the experiment, if you receive information, it has to be true. If you don't receive any information, this is principal's choice (and principal knows your and other agent's ability). If you don't receive any information, it means that the other agent did not receive any information either.

As in the previous treatment, the principals will also be asked to guess, for each agent, the probabilities of each state $(H H, H L, L H, L L)$ as stated by that agent. If the principal's guess is within \pm 5 percentage points of the agent's stated probability, he/she will earn $10 \mathrm{ECU}$ extra (for each successful 
Table 14: Risk Preference Elicitation

\begin{tabular}{cccc|cccc}
\hline \multicolumn{4}{c|}{ A } & \multicolumn{4}{c}{ B } \\
\hline Prob. & Payoff & Prob. & Payoff & Prob. & Payoff & Prob. & Payoff \\
\hline $10 \%$ & $60 \mathrm{ECU}$ & $90 \%$ & $45 \mathrm{ECU}$ & $10 \%$ & $100 \mathrm{ECU}$ & $90 \%$ & $10 \mathrm{ECU}$ \\
$20 \%$ & $60 \mathrm{ECU}$ & $80 \%$ & $45 \mathrm{ECU}$ & $20 \%$ & $100 \mathrm{ECU}$ & $80 \%$ & $10 \mathrm{ECU}$ \\
$30 \%$ & $60 \mathrm{ECU}$ & $70 \%$ & $45 \mathrm{ECU}$ & $30 \%$ & $100 \mathrm{ECU}$ & $70 \%$ & $10 \mathrm{ECU}$ \\
$40 \%$ & $60 \mathrm{ECU}$ & $60 \%$ & $45 \mathrm{ECU}$ & $40 \%$ & $100 \mathrm{ECU}$ & $60 \%$ & $10 \mathrm{ECU}$ \\
$50 \%$ & $60 \mathrm{ECU}$ & $50 \%$ & $45 \mathrm{ECU}$ & $50 \%$ & $100 \mathrm{ECU}$ & $50 \%$ & $10 \mathrm{ECU}$ \\
$60 \%$ & $60 \mathrm{ECU}$ & $40 \%$ & $45 \mathrm{ECU}$ & $60 \%$ & $100 \mathrm{ECU}$ & $40 \%$ & $10 \mathrm{ECU}$ \\
$70 \%$ & $60 \mathrm{ECU}$ & $30 \%$ & $45 \mathrm{ECU}$ & $70 \%$ & $100 \mathrm{ECU}$ & $30 \%$ & $10 \mathrm{ECU}$ \\
$80 \%$ & $60 \mathrm{ECU}$ & $20 \%$ & $45 \mathrm{ECU}$ & $80 \%$ & $100 \mathrm{ECU}$ & $20 \%$ & $10 \mathrm{ECU}$ \\
$90 \%$ & $60 \mathrm{ECU}$ & $10 \%$ & $45 \mathrm{ECU}$ & $90 \%$ & $100 \mathrm{ECU}$ & $10 \%$ & $10 \mathrm{ECU}$ \\
$100 \%$ & $60 \mathrm{ECU}$ & $0 \%$ & $45 \mathrm{ECU}$ & $100 \%$ & $100 \mathrm{ECU}$ & $0 \%$ & $10 \mathrm{ECU}$ \\
\hline
\end{tabular}

guess). At the end of the experiment, these extra earnings in the chosen round will be added to the payoff from that round. ${ }^{35}$

Do you have any questions?

Now, there will be an extra part where you can earn additional rewards.

\section{Extra Part (Risk Preference Elicitation)}

In this part you will be provided with two options that involve rewards that depend on chance. You may think about them as two lotteries.

Lottery A: Either gives $60 \mathrm{ECU}$ (High prize), or $45 \mathrm{ECU}$ (Low prize)

Lottery B: Either gives 100 ECU (High prize) or 15 ECU (Low prize)

You will be asked a series of questions that involve choosing between lottery A and B. The probability of winning the high prize (in the lottery you choose) will change from 0.1 to 1 . For each probability of winning you will be asked to state which lottery you prefer, lottery A or B. Among these 10 decisions, only one decision will be randomly selected by the computer, and you will earn rewards based on your decision in that particular question. (See Table 14.)

\section{Survey:}

Now you will be asked to answer several questions that will come up on your screen. Thank you again for your participation.

[Survey: see Section B.3]

\section{B.2 Quiz}

1. Assume that your ability is high and the other agent's ability is low. How much effort do you need to exert to maximize your payoff?
(a) 12
(b) 14
(c) 16
(d) 5

\footnotetext{
${ }^{35}$ Screenshots of the principal's and the agents' decision and guess screens were shown on the slides. These are available upon request.
} 
2. Assume that your ability is low and the other agent's ability is high. How much effort do you need to exert to maximize your payoff?
(a) 2
(b) 6
(c) 10
(d) 14

\begin{tabular}{|c|c|}
\hline Agent's guesses about his/her own and other agent's ability & $\%$ \\
\hline I have high ability, the other agent has low ability & 10 \\
\hline Both of us have high ability & 0 \\
\hline Both of us have low ability & 60 \\
\hline I have low ability, the other agent has high ability & 30 \\
\hline
\end{tabular}

3. Suppose you stated the above chances for each ability combination. Assume that the computer chose the "Both of us have low ability" and picks the winning probability in the chance mechanism as $50 \%$. Which of the following is true?

(a) My probability of earning 10 ECU is $50 \%$, and my payoff is independent of both agents' abilities.

(b) My payoff is 10 ECU if both of us have low ability, and 0 ECU otherwise.

\begin{tabular}{|c|c|}
\hline Agent's guesses about his/her own and other agent's ability & $\%$ \\
\hline I have high ability, the other agent has low ability & 10 \\
\hline Both of us have high ability & 0 \\
\hline Both of us have low ability & 60 \\
\hline I have low ability, the other agent has high ability & 30 \\
\hline
\end{tabular}

4. Suppose you stated the above chances for each ability combination. Assume that the computer chose the state "I have low ability, the other agent has high ability" and picks the winning probability in the chance mechanism as $60 \%$. Which of the following is true?

(a) My probability of earning $10 \mathrm{ECU}$ is $60 \%$, and my payoff is independent of both agents' abilities.

(b) My payoff is 10 ECU if I have low ability and the other agent has high ability, and 0 ECU otherwise.

\section{B.3 Post-experiment Survey Questions}

1. How old are you?

2. What is your gender?

3. Which year of your degree program are you in? 
4. What is your major?

5. What is your current GPA?

6. Were the rules of the experiment clear and understandable? Please answer on a scale of 1 to 10: $1=$ not understandable at all, $10=$ extremely understandable. 